\title{
The Claudin-like Protein HPO-30 Is Required to Maintain LAChRs at the C. elegans Neuromuscular Junction
}

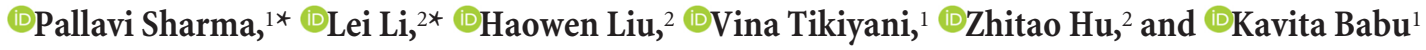 \\ ${ }^{1}$ Department of Biological Sciences, Indian Institute of Science Education and Research Mohali, Knowledge City, Punjab, India and ${ }^{2} Q u e e n s l a n d ~ B r a i n$ \\ Institute, Clem Jones Centre for Ageing Dementia Research, University of Queensland, St. Lucia, Queensland 4072, Australia
}

Communications across chemical synapses are primarily mediated by neurotransmitters and their postsynaptic receptors. There are diverse molecular systems to localize and regulate the receptors at the synapse. Here, we identify HPO-30, a member of the claudin superfamily of membrane proteins, as a positive regulator for synaptic localization of levamisole-dependent AChRs (LAChRs) at the Caenorhabditis elegans neuromuscular junction (NMJ). The HPO-30 protein localizes at the NMJ and shows genetic and physical association with the LAChR subunits LEV-8, UNC-29, and UNC-38. Using genetic and electrophysiological assays in the hermaphrodite C. elegans, we demonstrate that HPO-30 functions through Neuroligin at the NMJ to maintain postsynaptic LAChR levels at the synapse. Together, this work suggests a novel function for a tight junction protein in maintaining normal receptor levels at the NMJ.

Key words: AChRs; HPO-30; levamisole; neuromuscular junction

\section{Significance Statement}

Claudins are a large superfamily of membrane proteins. Their role in maintaining the functional integrity of tight junctions has been widely explored. Our experiments suggest a critical role for the claudin-like protein, HPO-30, in maintaining synaptic levamisole-dependent AChR (LAChR) levels. LAChRs contribute to $<20 \%$ of the acetylcholine-mediated conductance in adult Caenorhabditis elegans; however, they play a significant functional role in worm locomotion. This study provides a new perspective in the study of LAChR physiology.

\section{Introduction}

Claudins are tetraspanin membrane proteins that play crucial roles in the formation and integrity of tight junctions and in regulating paracellular transport. Claudin proteins also function

Received Dec. 11, 2017; revised June 7, 2018; accepted June 7, 2018.

Author contributions:P.S., L.L., Z.H., and K.B. designed research;P.S., L.L., H.L., and V.T. performed research;P.S., L.L., Z.H., and K.B. analyzed data; P.S., L.L., Z.H., and K.B. wrote the paper.

WormBase was supported by National Human Genome Research Institute Grant U41 HG002223, U.S. National Institutes of Health, United Kingdom Medical Research Council, and United Kingdom Biotechnology and Biological Sciences Research Council. The Caenorhabditis Genetics Center Minneapolis was supported by the U.S. National Institutes of Health Office of Research Infrastructure Programs (P40 0D010440). P.S. was supported by an Indian Council of Medical Research fellowship and WT-DBT India Alliance fellowship to K.B., V.T. was supported by the Council of Scientific and Industrial Research for a graduate fellowship. K.B. is an Intermediate Fellow of the Wellcome Trust-DBT India Alliance (Grant IA/I/12/1/500516). K.B. was also supported by DBT-IYBA Grant BT/05/IYBA/2011 and Indian Institute of Science Education and Research Mohali. Z.H. was supported by NHMRC Project Grant APP1122351 and ARC Discovery Project Grant DP160100849. All vectors used in this study were obtained from Addgene. We thank the members of the K.B. laboratory for comments on the manuscript; Jean-Louis Bessereau, Erik Jorgensen, Wayne Forrester, Josh Kaplan, Erik Lundquist, Villy Maricq, Kang Shen and Derek Sieburth for strains; Josh Kaplan for multiple marker lines; Ankit Negi for routine help; the Indian Institute of Science Education and Research Mohali Confocal facility for the use of the confocal microscope; WormBase; and the Caenorhabditis Genetics Center. The authors declare no competing financial interests.

*P.S. and L.L. contributed equally to this study as co-first authors.

Correspondence should be addressed to either of the following: Dr. Zhitao Hu, Queensland Brain Institute, Clem Jones Centre for Ageing Dementia Research, University of Queensland, Upland Road 79, St. Lucia, QLD 4072, Australia, E-mail: z.hu1@uq.edu.au; or Dr. Kavita Babu, Department of Biological Sciences, Indian Institute of Science to regulate channel activity, intercellular signaling, and cell morphology (Turksen and Troy, 2004; Angelow et al., 2008). Expression of claudins in different organs and the deregulation of these proteins are associated with diseases, such as cancers, renal disorders, and deafness (Singh et al., 2010; Goncalves et al., 2013). In the nervous system, claudins serve as an integral component of the blood-brain barrier by regulating paracellular ion selectivity (Matter and Balda, 2003; Papadopoulos et al., 2004).

Most claudins have a PDZ binding motif at their $\mathrm{C}$ terminus that allows binding to the PDZ domains of cytoplasmic scaffold proteins, such as ZO-1/2/3, PATJ, and MUPP1. This association allows for claudins to form connections with the actin cytoskeleton (Itoh et al., 1999; Hamazaki et al., 2002; Sawada et al., 2003). Further, claudins are known to interact with nontight junction proteins, such as cell adhesion molecules EpCam, tetraspanin, and signaling proteins, such as ephrin A, ephrin B, and their

Education and Research Mohali, Knowledge City, Sector 81, SAS Nagar, Mohali 140 306, Punjab, India, E-mail: kavitababu@iisermohali.ac.in or kavita.babu@babulab.org.

D0I:10.1523/JNEUROSCI.3487-17.2018

Copyright $\odot 2018$ Sharma, Li et al.

This is an open-access article distributed under the terms of the Creative Commons Attribution License Creative Commons Attribution 4.0 International, which permits unrestricted use, distribution and reproduction in any medium provided that the original work is properly attributed. 
receptors EphA and EphB (Ladwein et al., 2005; Tanaka et al., 2005a,b; Kovalenko et al., 2007; Rubinstein, 2011). The interaction of claudins with the actin cytoskeleton and with nontight junction proteins suggests that claudins might have functions other than in barrier formation. This work explores a nontight junction role for a Caenorhabditis elegans claudin-like protein, HPO-30.

The C. elegans genome encodes 18 claudins and claudin-like proteins ((Simske and Hardin, 2011) and wormbase (www. wormbase.org)). The functions of some of these claudin-like proteins have been studied. For example, CLC-1 localizes to epithelial cell junctions in the pharynx, where it regulates barrier functions (Asano et al., 2003). VAB-9, a divergent claudin-like protein, similar to vertebrate BCMP1 (brain cell membrane protein1), localizes to epithelial cell contacts and interacts with the cadherin-catenin complex during epidermal morphogenesis (Simske et al., 2003). Another protein, NSY-4, is related to the gamma subunit of voltage-gated calcium channels, TARP/Stargazin, as well as to other Claudin superfamily proteins. Previous studies have shown that the gamma subunit regulates the neuronal calcium channels and TARPs regulates AMPA-type glutamate receptor localization and activity (Heiskala et al., 2001; Arikkath and Campbell, 2003; Kang and Campbell, 2003; Van Itallie and Anderson, 2006). The C. elegans NSY-4 performs a dual function of regulating channel activity and adhesion function (Vanhoven et al., 2006). These functions of claudins in the regulation or recruitment of signaling proteins, cell adhesion molecules, and Ig proteins suggest important roles for claudins in the development and/or functioning of the nervous system.

To identify the function of the claudin family proteins at the C. elegans neuromuscular junction (NMJ), we performed an aldicarb-based screen on all available claudin mutants. We found mutants of a claudin homolog, hpo-30, to be extremely resistant to aldicarb. HPO-30 has previously been shown to be involved in the stabilization of dendritic branching of PVD neurons (Smith et al., 2013; O'Brien et al., 2017). Very recent studies show that HPO-30 functions through the WAVE regulatory complex and the membrane protein DMA-1 to allow for F-actin assembly and normal dendritic branching of the PVD neuron (Zou et al., 2018). Here we show that HPO-30 is required for the maintenance of levamisole sensitive AChRs (LAChRs) at the NMJ. Using genetic and electrophysiological analyses, we show that HPO-30 functions through Neuroligin/NLG-1 to maintain LAChRs at the NMJ. Together, our data implicate HPO-30 specifically in LAChR maintenance at the C. elegans NMJ.

\section{Materials and Methods}

\section{Strains}

All strains were maintained at $20^{\circ} \mathrm{C}$ as described previously (Brenner, 1974). The E. coli strain OP50 was used for seeding the C. elegans plates. The Bristol N2 strain was used as the wild-type (WT) control strain. The mutant strains used in this study were as follows: hpo-30 (ok2047), nlg-1 (ok259), nrx-1 (ok1649), and lev-8 (ok1519) (Jospin et al., 2009; Calahorro and Ruiz-Rubio, 2012, 2013; Hu et al., 2012; Smith et al., 2013). Further description of these alleles is available at wormbase (www. wormbase.org). All experiments in this study were performed using hermaphrodite C. elegans.

\section{Constructs and transgenes}

All constructs were generated using standard cloning procedures (Sambrook and Russell, 2001). pPD49.26 or pPD95.75 served as the vector backbone for all the constructs. The transcriptional reporter for $h p o-30$ was made by cloning a $3 \mathrm{~kb}$ region upstream of the $h p o-30$ start codon into the $p P D 95.75$ vector. $\mathrm{A} 3 \mathrm{~kb}$ myo-3 promoter was used for expression of HPO-30 in the body-wall muscles, and a $1.4 \mathrm{~kb} \mathrm{rab}-3$ promoter was used for expression of HPO-30 pan-neuronally. For all the rescue experiments, a $1.5 \mathrm{~kb}$ genomic fragment of $h p o-30$ was cloned downstream of the various promoters. For the HPO-30 colocalization experiment, the mCherry was cloned downstream of HPO-30 in the Pmyo-3::HPO-30 plasmids. All the constructs were sequenced, and transgenic lines were generated by microinjection as described previously (Mello et al., 1991; Mello and Fire, 1995). A complete list of the primers used in this study is available in Table 1, and a complete list of the plasmids and strains used in this study is detailed in Tables 2, 3, and 4.

\section{Behavioral assays}

Aldicarb assay. Aldicarb assays were performed as described previously (Harada et al., 1994; Miller et al., 1996; Nurrish et al., 1999). Plates containing $1 \mathrm{~mm}$ aldicarb (Sigma-Aldrich; 33386) were prepared $1 \mathrm{~d}$ before the assay and allowed to dry at room temperature. Young adult animals $(20-25)$ were picked and placed on aldicarb plates. The animals were scored for paralysis by gently prodding them after every $10 \mathrm{~min}$ with a pick, for up to $2 \mathrm{~h}$. The assays were performed in triplicates with the experimenter being blind to the genotype of the animals. For simplicity, the percentage of animals that were paralyzed at the $100 \mathrm{~min}$ time point was plotted.

Levamsiole assay. Tetramisole hydrochloride (Sigma-Aldrich; \# L9756) solution was prepared in water and dissolved in nematode growth medium to a concentration of $0.6 \mathrm{~mm}$. Young adults animals $(20-25)$ were placed on levamisole-containing plates seeded with OP50 and were monitored for paralysis after every $10 \mathrm{~min}$. The animals were scored for paralysis by tapping the plates on the bench as has been previously described (Gendrel et al., 2009; Rapti et al., 2011). Animals showing less than one body bend were scored as paralyzed. The assay was performed in triplicates with the experimenter being blind to the genotype of the animals. For simplicity, the percentage of animals that were paralyzed at the 100 min time point was plotted.

Muscimol assay. Muscimol (Sigma-Aldrich; \# G019) assays were performed as described previously (de la Cruz et al., 2003). Briefly, 10-12 animals were placed on plates containing $200 \mathrm{~mm}$ muscimol for $1 \mathrm{~h}$, after which the C. elegans behavior was analyzed by recording their response to touch. The animals were scored according to their movement or the pattern of contraction and relaxation cycle of the body. The behavior of C. elegans was classified into five categories: 0 , C. elegans did not contract or relax but moved away from the stimulus rapidly; 1 , C. elegans contract and relax briefly and then move away from the stimulus; 2 , animals contracted and relaxed while showing a small backward displacement; 3 , C. elegans contracted and relaxed but failed to move; and 4, animals contracted and relaxed incompletely with no displacement. The assay was performed in triplicates with the experimenter being blind to the genotype of the animals.

\section{Microscopy}

The imaging was done using a Axio Imager Z2 with an Axiocam MRm camera (Carl Zeiss). For imaging experiments, the animals were immobilized using $30 \mathrm{mg} / \mathrm{ml}$ BDM on $2 \%$ agarose pads. The analysis of images was done using the ImageJ software. For quantitative analysis, the fluorescence intensity of $\sim 25$ animals (actual number indicated at the base of each bar graph) was averaged and used to plot the graph using the Prism software (GraphPad). Data are expressed as mean \pm SEM. $p$ values were based on Student's $t$ test or one-way ANOVA. Images for muscle arms were acquired using the TCS SP8 confocal microscope (Leica), and the image processing was done using ImageJ software.

\section{$q P C R$}

The qPCR experiments were performed using total RNA extracted from mixed-stage animals using the RNA easy kit according to the manufacturer's instructions (QIAGEN). The RNA was transcribed to cDNA using the Transcriptor high-fidelity cDNA synthesis kit (Roche; \# 05081955001). The qPCR was performed using SYBR Green master mix (QIAGEN; \# 204141) using an Eppendorf thermal cycler.

\section{Antibody production}

The UNC-29 and UNC-38 antibodies were produced as previously described (Gally et al., 2004; Gendrel et al., 2009). Briefly, for the UNC-29 
Table 1. List of primers

\begin{tabular}{|c|c|c|c|}
\hline Primer code & Sequence & Comment & Gene \\
\hline PS104 & TTGGTGTGGCTCAGATTGTTC & Genotyping forward external & hpo-30 \\
\hline PS105 & AGAGGACTAAACAACGAGAACGCAG & Genotyping forward internal & hpo-30 \\
\hline PS106 & AATCTTGAGTGGCTCTGTTGG & Genotyping reverse external & hpo-30 \\
\hline ST223 & CGCGGGATAGTGACGAAA & Genotyping forward external & $n r x-1$ \\
\hline ST224 & CCATGCTCAACGAGAGAAGC & Genotyping forward internal & $n r x-1$ \\
\hline ST225 & CCTCCGGCCATCAACTATC & Genotyping reverse external & $n r x-1$ \\
\hline ST226 & GTGGATCCGTTCCGAAGA & Genotyping forward external & $n \lg -1$ \\
\hline ST227 & GAGAGCCCCTTATTCCACTG & Genotyping forward internal & $n \lg -1$ \\
\hline ST228 & GATGGACAGGTGGGTTGAAG & Genotyping reverse external & $n \lg -1$ \\
\hline PS344 & CATATGTATGTGTCTCTTGTTTCCG & Genotyping WT forward & lev-8 \\
\hline PS345 & CATATGTATGTGTCTCTTGTTTCCA & Genotyping mutant forward & lev-8 \\
\hline PS346 & TTGATCTGACGGAATGTGTA & Genotyping reverse & lev-8 \\
\hline PS284 & AACTGCAGCAGCGTTGTGTTTCTGAAGATG & Cloning forward Pstl & Phpo-30 \\
\hline PS285 & CGGGATCCGTACATAATTAATGGCATTCCG & Cloning reverse BamH1 & Phpo-30 \\
\hline PS402 & AATTAAGCTTAGTGATTATAGTCTCTGTTTTCGTTA & Cloning forward HindIII & Pmyo-3 \\
\hline PS403 & ACTTGTCGACCATTTCTAGATGGATCTAGTG & Cloning reverse Sall & Pmyo-3 \\
\hline PS453 & ACTTGTCGACTTATGTACAAATTTCTATTAGTCAC & Cloning forward Sall & HPO-30 \\
\hline PS454 & AATTACCGGTCATACTGCTGTCATCGTCAAT & Cloning reverse Sall & HPO-30 \\
\hline PS114 & ACTTAATGGCACGGATAGACAGAAGC & Cloning forward Aflll & Prab-3 \\
\hline PS115 & CCGCTCGAGTAACACTTCCTAGTAGTAATGCCTC & Cloning reverse $\mathrm{Xhol}$ & Prab-3 \\
\hline PS130 & CCGCTCGAGATGCCATTAATTATGTACA & Cloning forward Xho I & $\begin{array}{l}\text { hpo-30 } \\
\text { gDNA }\end{array}$ \\
\hline PS136 & GGACTAGTTCACATACTGCTGTCATCGTC & Cloning reverse Spe I & $\begin{array}{l}\text { hpo-30 } \\
\text { gDNA }\end{array}$ \\
\hline PS434 & AACTAGCTAGCATCTTTCGGTCGTTGGTACG & Cloning forward Nhel & $n \lg -1$ \\
\hline & & & RNAi \\
\hline PS435 & AAAACTGCAGCATTCACTTGGTTTGGGCTT & Cloning reverse Pstl & $\begin{array}{l}n l g-1 \\
\text { RNAi }\end{array}$ \\
\hline PS436 & AAAAACTGCAGAACAAACGTCGTGTGCATGT & Cloning forward Nhel & $\begin{array}{l}\text { hpo-30 } \\
\text { RNAi }\end{array}$ \\
\hline PS437 & AACTAGCTAGCTCCGTTCATTCCTCCAATTC & Cloning reverse Pstl & $\begin{array}{l}\text { hpo-30 } \\
\text { RNAi }\end{array}$ \\
\hline PS304 & CGGAATTCCTACTTATACAATTCATCCATGCCACC & Cloning reverse EcoRl & mCherry \\
\hline PS355 & AATTACCGGTATGGTCTCAAAGGGTGAAGAAG & Cloning forward Age I & mCherry \\
\hline PS371 & TGTTGCTCATCAATGTGGACG & Forward & $\begin{array}{l}\text { unc- } 29 \\
\text { qPCR }\end{array}$ \\
\hline PS372 & ACCTCGTAATTTCCATCGGCA & Reverse & $\begin{array}{l}\text { unc- } 29 \\
\text { qPCR }\end{array}$ \\
\hline PS373 & ACCTCGTAATTTCCATCGGCA & Forward & $\begin{array}{l}\text { unc-38 } \\
\text { qPCR }\end{array}$ \\
\hline PS374 & ATCGCCGAACTGCTGAAAAA & Reverse & $\begin{array}{l}\text { unc-38 } \\
\text { qPCR }\end{array}$ \\
\hline PS398 & TTGCAAAGTATCTTTTGCTCACT & Forward & $\begin{array}{l}\text { unc-63 } \\
\text { qPCR }\end{array}$ \\
\hline PS399 & TCAGTAATGGGAGAATATCAAGGAA & Reverse & $\begin{array}{l}\text { unc-63 } \\
\text { qPCR }\end{array}$ \\
\hline
\end{tabular}

\section{Table 2. List of plasmids}

\begin{tabular}{lll}
\hline Serial no. & Plasmid no. & Plasmid \\
\hline 1 & pBAB201 & Phpo-30::GFP \\
2 & pBAB203 & Prab-3::hpo-30 gDNA \\
3 & pBAB204 & Pmyo-3::hpo-30 gDNA \\
4 & pBAB205 & Punc-17::hpo-30 gDNA \\
5 & pBAB220 & Pmyo-3:: hpo-30 \\
& & gDNA::mCherry \\
6 & pBAB241 & nlg-7(RNAi) in L4440 \\
7 & pBAB242 & hpo-30(RNAi) in L4440 \\
\hline
\end{tabular}

antibody, a DNA fragment encoding 348-431 amino acids of the UNC-29 gene was inserted into pGEX-5X and for the UNC-38 antibody, a DNA fragment encoding 375-418 amino acids of the UNC-38 gene was cloned in pGEX-5X. The GST::UNC-29 and GST::UNC-38 fusion proteins were then expressed in BL21 Escherichia coli cells and purified. This fusion protein was then injected into the rabbits, and rabbits were boosted with $100 \mu \mathrm{g}$ each time. The antibody was then purified and used for experiments. The antibody production and purification were performed by Bioklone Biotech.

\section{Immunoprecipitation and Western blotting}

For protein extraction, mixed-stage animals were grown and stored at $-80^{\circ} \mathrm{C}$ until further use. While starting the protein extraction, ice-cold homogenization buffer was added to the C. elegans pellets. C. elegans lysate was prepared by grinding the animals in a mortar and pestle in presence of liquid nitrogen. The suspension was centrifuged at $5000 \times g$ for $10 \mathrm{~min}$ at $4^{\circ} \mathrm{C}$ to remove the debris. The supernatant was then centrifuged at high speed for $1 \mathrm{~h}$ at $4^{\circ} \mathrm{C}$. The pellet was then dissolved in $100-500 \mu \mathrm{l}$ of resuspension buffer as previously described (Gendrel et al., 2009). This fraction was then resolved on SDS-PAGE gel and blotted onto a nitrocellulose membrane. The membranes were then probed with the purified anti-UNC-29 (1:600) or anti-UNC-38 (1:1000) serum. Antirabbit secondary antibody (1:2000, IgG-AP \# sc-2007, Santa Cruz Biotechnology) was used to probe the blot and detection was done using the Pierce Alkaline phosphatase substrate kit. 
Table 3. List of integrated lines

\begin{tabular}{|c|c|c|c|}
\hline $\begin{array}{l}\text { Serial } \\
\text { no. }\end{array}$ & $\begin{array}{l}\text { Integrated } \\
\text { line no. }\end{array}$ & Plasmid & Source and reference \\
\hline 1 & nuls321 & Punc-17::mCherry & Josh Kaplan laboratory (Babu et al., 2011) \\
\hline 2 & Punc-17::ChIEF & Punc-17::ChlEF & From Erik Jorgensen laboratory \\
\hline 5 & nuls160 & Punc-129::SYD-2::GFP & Josh Kaplan laboratory (Sieburth et al., 2005) \\
\hline 4 & nuls299 & Pmyo-3::ACR-16::GFP & Josh Kaplan laboratory (Babu et al., 2011) \\
\hline 5 & hpls3 & Punc-25::SYD-2::GFP & CGC \\
\hline 6 & nuls283 & Pmyo-3::UNC-49::GFP & Josh Kaplan laboratory (Babu et al., 2011) \\
\hline 7 & cw/s6 & CAM-1::GFP & Wayne Forrester laboratory (Kim and Forrester, 2003) \\
\hline 8 & Ihls6 & Punc-25::mCherry & Erik Lundquist (Norris and Lundquist, 2011) \\
\hline 9 & akls38 & UNC-29::GFP & Villu Maricq laboratory (Francis et al., 2005) \\
\hline 10 & kr98::YFP & UNC-63:.:YFP & Jean-Louis Bessereau laboratory (Rapti et al., 2011) \\
\hline 11 & kr208::tagRFP & UNC-29::tagRFP & Jean-Louis Bassereau laboratory (Richard et al., 2013) \\
\hline 12 & vjls105 & Pnlg-1::NGL-1::GFP & Derek Sieburth laboratory (Staab et al., 2014) \\
\hline 13 & juls76 & Punc-25::GFP & Yishi Jin laboratory (Baran et al., 2010) \\
\hline 14 & wyEx5333 & Phlh-1::NLG-1 & Kang Shen laboratory (Maro et al., 2015) \\
\hline
\end{tabular}

Table 4. List of strains

\begin{tabular}{|c|c|c|c|}
\hline Strain & Genotype & Comments & Figure(s) \\
\hline BAB 206 & hpo-30 & CGC, RB1657 (outcrossed 4X) & $1-8$ \\
\hline BAB 253 & IndEx205 (hpo-30; Punc17::HP0-30) & & 1 \\
\hline BAB 254 & IndEx201 (Phpo-30::GFP) & & 1 \\
\hline BAB 208 & Ih/s6; IndEx201 (Phpo-30::GFP) & & 1 \\
\hline BAB 211 & nuls321; IndEx201 (Phpo-30::GFP) & & 1 \\
\hline BAB 252 & IndEx204 (hpo-30; Pmyo-3::HPO-30) & & 1,4 , and 5 \\
\hline BAB 251 & IndEx203 (hpo-30; Prab-3::HP0-30) & & 1,4 , and 5 \\
\hline BAB 239 & hpo-30; Punc-17::ChIEF & & 3 \\
\hline BAB 207 & hpo-30;nuls321 & & 2 \\
\hline BAB 205 & hpo-30;juls76 & & 2 \\
\hline BAB 209 & hpo-30; nuls160 & & 2 \\
\hline BAB 210 & hpo-30; hpls3 & & 2 \\
\hline BAB 249 & hpo-30; nuls299 & & 5 \\
\hline BAB 246 & hpo-30; UNC-63::YFP & & 5 \\
\hline BAB 228 & hpo-30; ak/s38 & & 5 \\
\hline BAB 242 & Cwls6; UNC-29::tagRFP & & 5 \\
\hline BAB 243 & hpo-30; Cwls6; UNC-29::tagRFP & & 5 \\
\hline BAB 250 & hpo-30; nuls283 & & 5 \\
\hline BAB 232 & lev-8 & CGC, VC1041 (outcrossed 3×) & 5 \\
\hline BAB 239 & hpo-30; lev-8 & & 5 \\
\hline BAB 256 & $\begin{array}{l}\text { IndEx220 akls38; (Pmyo-3::HP0-30:: } \\
\text { mCherry) }\end{array}$ & & 6 \\
\hline BAB 262 & $n l g-1$ & CGC, VC1416 (outcrossed 3×) & 7 and 8 \\
\hline BAB 261 & $n r x-1$ & CGC, VC228 (outcrossed 4X) & 7 and 8 \\
\hline BAB 241 & nrx-1 hpo-30 & & 7 and 8 \\
\hline BAB 245 & hpo-30;nlg-1 & & 7 and 8 \\
\hline BAB 247 & nlg-1; Punc-17::ChIEF & & 8 \\
\hline BAB 248 & nrx-1; Punc-17::ChIEF & & 8 \\
\hline BAB 257 & hpo-30; vils105 & & 8 \\
\hline BAB 275 & hpo-30; UNC-29::tagRFP & & 8 \\
\hline BAB 276 & hpo-30; nlg-1; UNC-29::tagRFP & & 8 \\
\hline BAB 277 & nlg-1; UNC-29::tagRFP & & 8 \\
\hline
\end{tabular}

To perform the coimmunoprecipitation experiment, C. elegansexpressing HPO-30::mCherry in muscles was grown in multiple plates (40 plates of $90 \mathrm{~mm}$ diameter). The animals were collected using M9 buffer, and they were washed three times with the M9 buffer to get rid of the OP50. The protein was prepared using a previously described protocol (Gendrel et al., 2009). Next, $3 \mathrm{mg}$ of protein sample was incubated with UNC-29 and UNC-38 antibodies at $4^{\circ} \mathrm{C}$ for $4 \mathrm{~h} ; 50 \mu \mathrm{l}$ of equilibrated protein A/G beads (Merck Millipore \#16-125) was added to the lysate and further incubated for $3 \mathrm{~h}$. Next, the beads were washed 5 times with ice-cold lysis buffer. The protein was then eluted in $30 \mu \mathrm{l}$ of sample loading buffer by boiling for $5 \mathrm{~min}$. Western blotting was performed using mCherry rat antibody (Molecular Probes \# M11217) at 1:1000 dilution. We used HRP-labeled antirat secondary antibody at a dilution of 1:5000. Protein detection was done using the GE enhanced chemiluminescent detection reagent.

\section{Electrophysiological recordings}

Electrophysiology was done on dissected C. elegans as previously described (Hu et al., 2012; Liu et al., 2018). The C. elegans was superfused in an extracellular solution containing $127 \mathrm{~mm} \mathrm{NaCl}, 5 \mathrm{~mm} \mathrm{KCl}, 26 \mathrm{~mm}$ $\mathrm{NaHCO}_{3}, 1.25 \mathrm{~mm} \mathrm{NaH}_{2} \mathrm{PO}_{4}, 20 \mathrm{~mm}$ glucose, $1 \mathrm{~mm} \mathrm{CaCl}$, and $4 \mathrm{~mm}$ $\mathrm{MgCl}_{2}$, bubbled with $5 \% \mathrm{CO}_{2} / 95 \% \mathrm{O}_{2}$ at $20^{\circ} \mathrm{C}$. Whole-cell recordings were performed at $-60 \mathrm{mV}$ (reversal potential of $\mathrm{GABA}_{\mathrm{A}}$ receptors) for mEPSCs and $0 \mathrm{mV}$ (reversal potential of AChRs) for mIPSCs. The internal solution contains $105 \mathrm{~mm} \mathrm{CH}_{3} \mathrm{O}_{3} \mathrm{SCs}, 10 \mathrm{~mm} \mathrm{CsCl}, 15 \mathrm{~mm} \mathrm{CsF}, 4 \mathrm{~mm}$ $\mathrm{MgCl}_{2}, 5 \mathrm{~mm}$ EGTA, $0.25 \mathrm{~mm} \mathrm{CaCl}_{2}, 10 \mathrm{~mm}$ HEPES, and $4 \mathrm{~mm} \mathrm{Na}_{2} \mathrm{ATP}$, adjusted to $\mathrm{pH} 7.2$ using $\mathrm{CsOH}$. Stimulus-evoked EPSCs were stimulated by placing a borosilicate pipette $(51 \mu \mathrm{m})$ near the ventral nerve cord (one muscle distance from the recording pipette) and applying a $0.4 \mathrm{~ms}, 85 \mu \mathrm{A}$ square pulse (WPI). To measure levamisole-activated currents, a puffing pipette (5-10 $\mu \mathrm{m}$ open size) containing $0.5 \mathrm{~mm}$ levamisole was placed at the end of the patched muscle, and a $100 \mathrm{~ms} 20 \mathrm{kPa}$ pressure was applied via Picospritzer (Parker).

Statistical analysis

Statistical values for each set of genotypes compared through Student's $t$ test are indicated as $p, t$, and $d f$.

\section{Results}

\section{Mutants of $h p o-30$, a claudin-like protein, are resistant to aldicarb}

To understand the function of claudins at the NMJ, we screened through all available claudin mutants using the acetylcholine esterase inhibitor, aldicarb. Aldicarb causes an increase in the levels of acetylcholine and hence results in increased muscle contraction in the animal, which in turn leads to paralysis. Mutants with altered synaptic function show increased or decreased rates of paralysis compared with WT C. elegans (Miller et al., 1996; Sieburth et al., 2005; Vashlishan et al., 2008).

In this screen, we found that a deletion (likely null) mutant of hpo-30 (ok2047) that removes $1.2 \mathrm{~kb}$ of the coding region, including exons 1-3 showed an extremely resistant phenotype upon exposure to aldicarb compared with WT animals (WT and hpo$30, p=0.0002, t=22, \mathrm{df}=4$; Fig. $1 A, B)$. HPO-30 encodes a four-transmembrane domain protein with similarity to members of the claudin-like family of proteins.

Previous studies have shown the expression of HPO-30 in FLP, PVD, tail, and ventral cord neurons and that it is required for stabilizing dendritic branching in PVD neurons (Smith et al., 2013). Because we were interested in understanding the role of $\mathrm{HPO}-30$ at the NMJ, we planned to evaluate the expression of the 
A

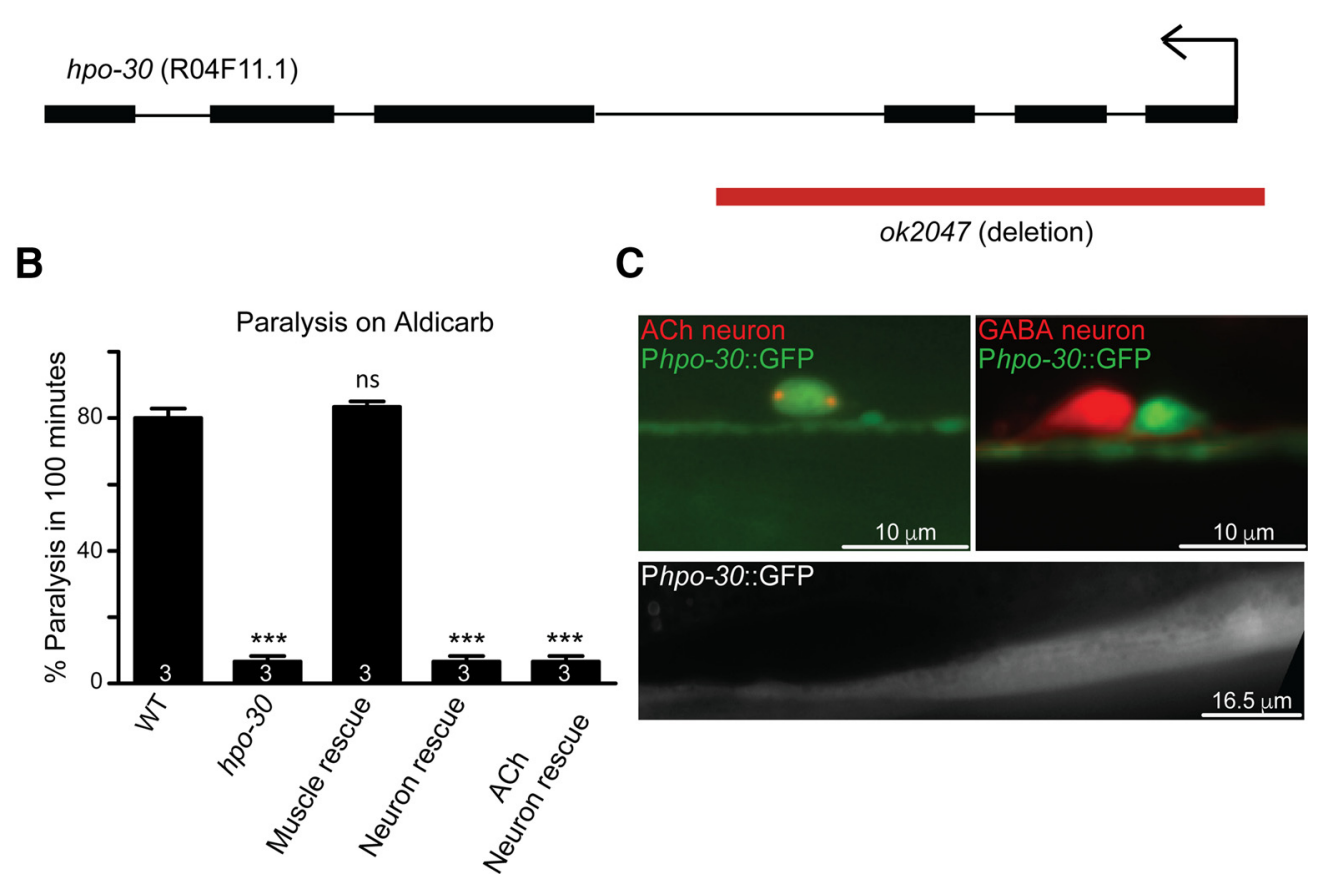

Figure 1. Mutants in $h p 0-30$ are resistant to aldicarb. $A$, Schematic of the $h p o-30$ gene. Black boxes represent the coding exons. Red bar represents the ok2047 deletion. $B$, Aldicarb assay of WT, hpo-30 mutants, and site-specific rescue of HPO-30. Bar graphs represent the percentage of animals paralyzed at the $100 \mathrm{~min}$ time point. In all the aldicarb graphs, the number at the base of the bars indicates the number of times the assay was performed with $20-25$ C. elegans used for each trial. Data are mean \pm SEM. ${ }^{* * *} p<0.001$. C, Transcriptional reporter of $h p o-30$ shows expression in cholinergic neurons and not in GABAergic neurons, which were identified by Punc-17::mCherry and Punc-25::mCherry, respectively. Phpo-30::GFP also shows expression in body-wall muscles. ns, not significant.

hpo-30 promoter in motor neurons and/or body-wall muscles. To achieve this, we made a GFP transcriptional reporter containing a $3 \mathrm{~kb}$ upstream region of $h p o-30$ and analyzed the expression of this promoter fusion. We observed the expression of HPO-30 in the ventral cord motor neurons as previously reported, further diffuse expression was present in the body-wall muscles (data not shown; and Fig. 1C) (Smith et al., 2013). To identify the HPO30-expressing neurons, we performed a double-labeling experiment and found that the GFP-tagged hpo-30 promoter showed coexpression with mCherry-labeled cholinergic neurons and not with GABAergic neurons (Fig. 1C).

Because the $h p o-30$ promoter showed expression in cholinergic neurons and body-wall muscle, we next went on to find the site of action of HPO-30. To achieve this, we expressed HPO-30 specifically in the body-wall muscles, pan-neuronally and in cholinergic neurons. The data from the rescue experiments indicated that the aldicarb resistance in hpo-30 mutants could be rescued only when HPO-30 was expressed specifically in the body-wall muscles (WT and hpo-30; Pmyo-3::HPO-30, $p=0.3910, t=1$, df $=3$; Fig. $1 B$ ).

Because HPO-30 showed expression in presynaptic cholinergic neurons and postsynaptic body-wall muscles, we next wanted to see whether the mutants showed defects in synaptic development.

\section{Synapse morphology is normal in hpo-30 mutants}

The decreased responsiveness of hpo-30 mutant animals toward aldicarb could be due to altered neuronal or synapse development. To check for developmental defects in neurons and synapses, we went on to look at a set of neuronal and synaptic markers in the hpo-30 mutant animals. Loss of hpo-30 did not appear to have any obvious developmental defects on the cholin- ergic or GABAergic motor neurons (Fig. 2A). Further, both cholinergic and GABAergic synapses at the NMJ appeared to be formed normally as seen using the active zone marker $\alpha$-liprin/ SYD-2 expressed specifically in cholinergic or GABAergic neurons, respectively (WT and $h p o-30, p=0.6081, t=0.5168, \mathrm{df}=$ 41; Fig. 2B; and WT and $h p o-30, p=0.5299, t=0.6331, \mathrm{df}=41$; Fig. $2 C$ ). Together, these results suggest that the decreased rate of paralysis shown by $h p o-30$ mutant animals is unlikely to be due to developmental defects of neurons or synapses.

\section{hpo-30 mutants have normal synaptic vesicle release at the NMJ}

The aldicarb resistance phenotype showed by $h p o-30$ mutants and the expression of Phpo-30::GFP in cholinergic neurons and body-wall muscles indicated a role for HPO-30 in either promoting the vesicle release machinery or maintaining the acetylcholine reception machinery. To assay synaptic transmission, we measured EPSCs and IPSCs from the body-wall muscles (Richmond, 2006; $\mathrm{Hu}$ et al., 2012). The amplitude and rate of endogenous EPSCs and IPSCs were unaltered in $h p o-30$ mutants (Fig. $3 A-D$ : frequency WT and hpo-30, $p=0.8281, t=0.2195$, df $=24$; amplitude, $p=0.5499, t=0.6065, \mathrm{df}=24$; Fig. $3 C$; WT and hpo-30 frequency, $p=0.6177, t=0.5123$, df $=12$; and amplitude, $p=0.8981, t=0.1308, \mathrm{df}=12$; Fig. $3 D$ ). This suggests that synaptic transmission at the cholinergic and GABAergic NMJs is largely normal. Further, we looked at the muscle responsiveness by measuring the evoked currents and found that there were no significant changes in the amplitude and charge transfer of evoked EPSCs in the $h p o-30$ animals compared with WT controls (Fig. 3E: evoked EPSC amplitude WT and $h p o-30, p=0.9087, t=$ $0.1160, \mathrm{df}=22$; and charge, $p=0.8852, t=0.1461, \mathrm{df}=22$; Fig. $3 F$ ). The C. elegans body-wall muscle possesses two types of cho- 
A
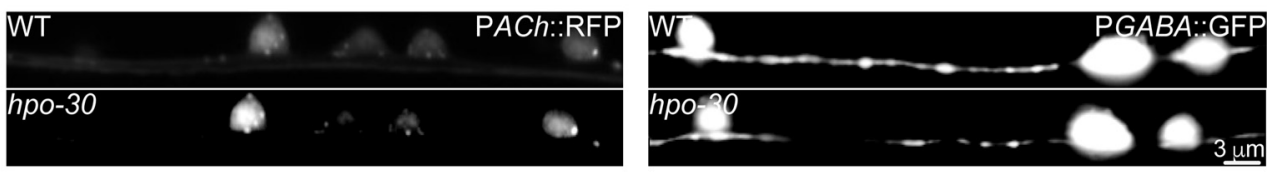

B
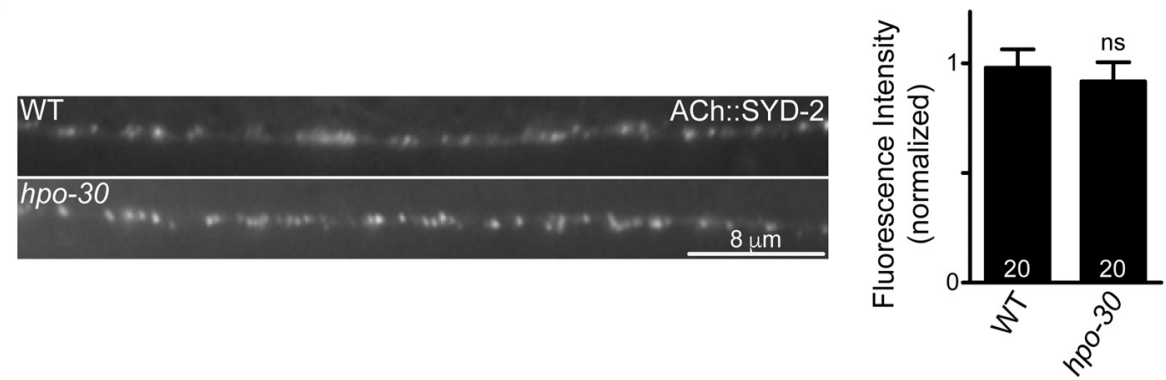

C
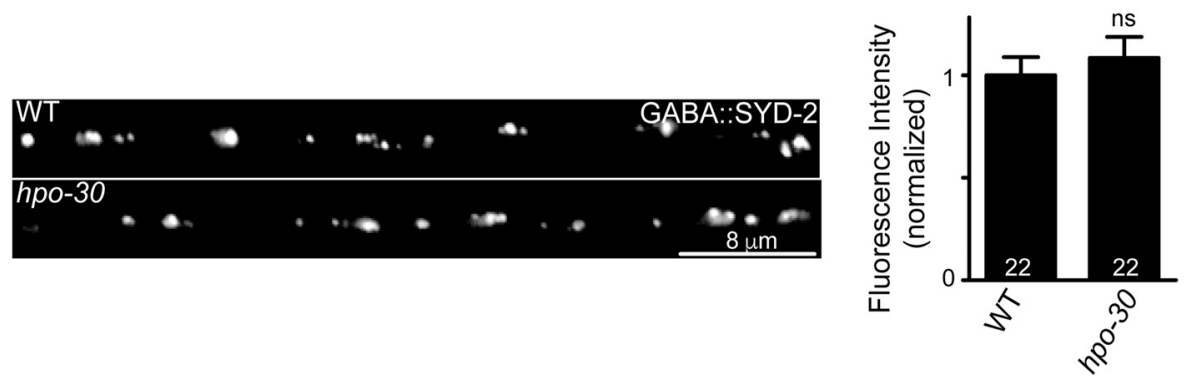

Figure 2. hpo-30 mutants have normal neuromuscular synapses. $\boldsymbol{A}$, Expression of Punc-17::mCherry and Punc-25::GFP in WT and hpo-30 mutant animals. $\boldsymbol{B}$, Representative images and quantification for the active zone protein SYD-2 along the dorsal cord axons of cholinergic neurons in WT and hpo-30 C. elegans. C, Representative images and quantification for active zone protein SYD-2 in dorsal cord axons of GABAergic neurons in WT and hpo-30 animals. Data are mean \pm SEM. ns, not significant.

linergic receptors: ACR-16 and LAChRs (Lewis et al., 1980; Fleming et al., 1997; Richmond and Jorgensen, 1999; Culetto et al., 2004; Touroutine et al., 2005; Towers et al., 2005). ACR-16 receptors account for $\sim 90 \%$ of the postsynaptic currents in $C$. elegans, and changes in ACR-16 levels affect the amplitude of the EPSCs and cause changes in the evoked EPSC current amplitudes (Francis et al., 2005; Touroutine et al., 2005; Babu et al., 2011). Hence, these data showing no significant changes in evoked EPSC amplitude suggest that HPO-30 does not appear to affect ACR-16 receptors. We next went on to further test whether HPO-30 is required for normal postsynaptic receptor function.

HPO-30 is required for normal LAChR-dependent functions The decreased rate of paralysis of hpo-30 mutants in the presence of aldicarb and the ability to rescue this defect by expressing HPO-30 specifically in body-wall muscles suggest that HPO-30 could function in the body-wall muscles for maintaining normal aldicarb response.

The C. elegans NMJ expresses receptors that respond to both cholinergic and GABAergic neurotransmitters functioning at the body-wall muscles (Richmond and Jorgensen, 1999). To explore the possibility that HPO-30 could affect receptor function at the body-wall muscles and thereby show altered aldicarb sensitivity, we performed pharmacological experiments to assay for defects in cholinergic and GABAergic receptors.

As stated previously, the cholinergic receptors include two classes of nicotinic AChRs: the homomeric AChR/ACR-16 receptors and the heteropentameric LAChRs, which are activated spe- cifically by the drug levamisole (Lewis et al., 1980; Fleming et al., 1997; Richmond and Jorgensen, 1999; Culetto et al., 2004; Touroutine et al., 2005; Towers et al., 2005). Levamisole is an agonist of the AChR and causes muscle hypercontraction, leading to the paralysis of the animals. Mutants lacking the ACR-16 receptors have a mild change in aldicarb sensitivity, whereas mutants lacking the LAChRs exhibit strong resistance to aldicarb (Lewis et al., 1980; Daniels et al., 2000; Babu et al., 2011), suggesting that HPO-30 may regulate the functioning of LAChRs. To see whether hpo-30 mutants affected LAChRs, we performed a levamisole assay using the $h p o-30$ mutant animals (Lewis et al., 1980; Gally et al., 2004). Mutants in hpo-30 showed resistance to paralysis in the presence of levamisole (WT and hpo-30, $p<$ $0.0001, t=20.12$, df $=4)$; this resistance was rescued by the expression of HPO-30 specifically in the body-wall muscles and not in motor neurons (WT and hpo-30; Pmyo-3::HPO-30, $p=$ $0.6779, t=0.4472, \mathrm{df}=4$; Fig. $4 A$ ). This experiment indicated that HPO-30 could be affecting LAChRs at the body-wall muscle. We also performed assays for defects in the GABA receptor at the NMJ using the drug muscimol, which is a GABA receptor agonist (de la Cruz et al., 2003). In the presence of muscimol, we saw no difference between WT and hpo-30 mutant animals, indicating that loss of $h p o-30$ does not appear to affect GABA receptors (Severity 2, $p=1.00, t=0.0, \mathrm{df}=2$; Severity $3, p=0.2929, t=$ $1.414, \mathrm{df}=2$; Fig. $4 B$ ).

Because all our data so far indicate that $h p o$-30 does not appear to affect either the amplitude of the EPSCs or the evoked currents, 
A

mEPSC

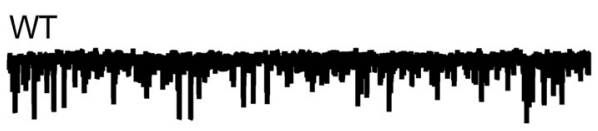

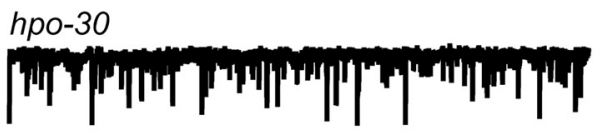

C
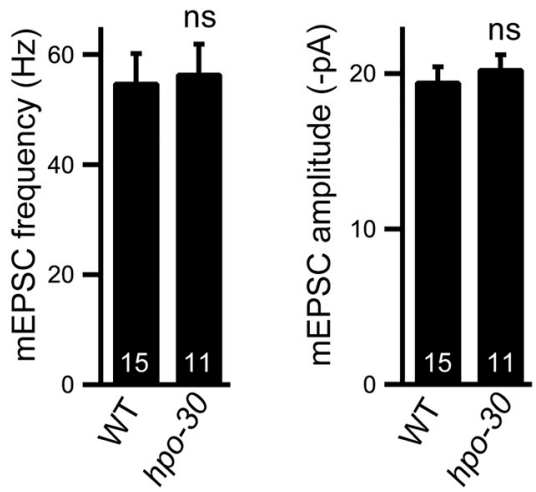

E

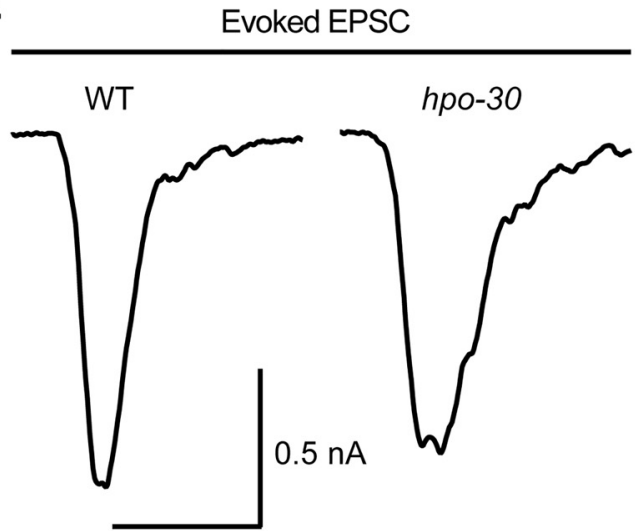

B
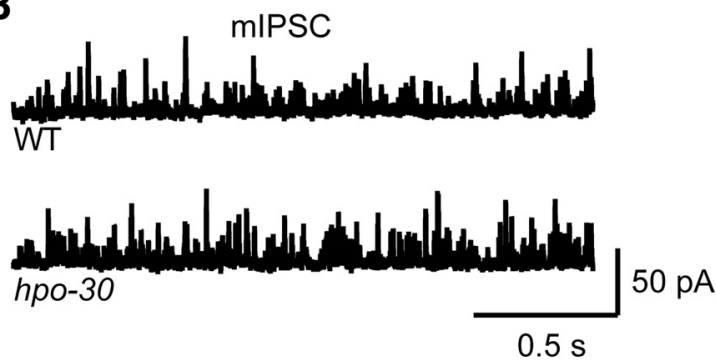

D
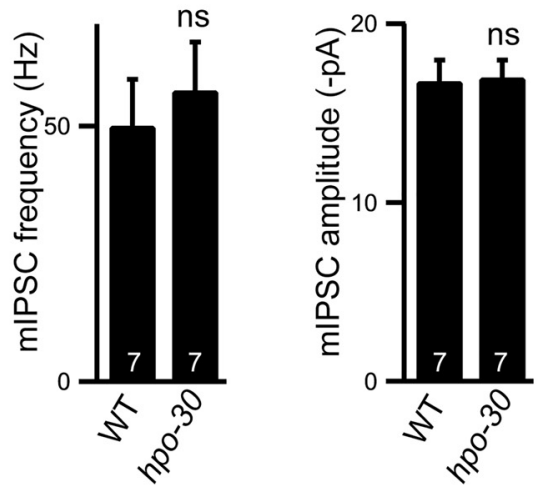

$\mathbf{F}$

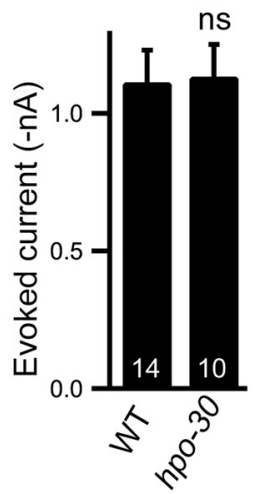

Figure 3. Endogenous and evoked neurotransmitter release is normal in $h p 0-30$ mutants. $A$, Representative trace of endogenous EPSC recordings from body-wall muscles of adult WT and hpo-30 animals. $\boldsymbol{B}$, Representative trace of endogenous IPSC recordings from body-wall muscle of adult WT and hpo-30 mutants. C, Average frequency and average amplitude of EPSCS of WT and hpo-30 mutants. The numbers at the base of the bars indicate the number of animals recorded in all figures. $D$, Average frequency and average amplitude of IPSCs for WT and $h p o-30$ mutant $C$. elegans. $\boldsymbol{E}$, Trace of stimulus-evoked response measured from the body-wall muscles of adult animals. $\boldsymbol{F}$, Summary data of evoked currents in WT and $h p o-30$ mutants. Data are mean \pm SEM.

we hence reasoned that HPO-30 was unlikely to be affecting ACR-16 levels at the NMJ (Fig. $3 A, C, E, F$ ).

To better understand the functional consequence of this decreased sensitivity toward levamisole, we recorded the levamisole puff response of body-wall muscles in hpo-30 mutant animals using previously described protocols (Richmond, 2006; Hu et al., 2012). We observed a large decrease in the amplitude of the currents in hpo-30 mutants compared with WT animals (WT and $h p o-30, p<0.0001, t=29.37, \mathrm{df}=14$ ). Again, this decrease in levamisole puff response was rescued by expressing HPO-30 in the body-wall muscles (WT and hpo30; Pmyo-3::HPO-30, $p=0.5674, t=0.5868$, df $=13$; Fig. $4 C, D$ ), whereas HPO-30 expression pan-neuronally could not rescue this phenotype (WT and hpo-30; Prab-3::HPO-30, $p<$ $0.0001, t=27.58, \mathrm{df}=12$; Fig. $4 C, D$ ). The above data strongly suggest that HPO-30 functions in the body-wall muscles to maintain the function of LAChRs. These results prompted us to look at LAChR levels at the NMJ.

HPO-30 is involved in the maintenance of LAChR levels at the NMJ

Decreased sensitivity of hpo-30 mutants to levamisole could be the result of altered expression or function of LAChRs. The LAChRs are pentameric receptors composed of five subunits: UNC-29, UNC-63, UNC-38, LEV-8, and LEV-1 (Fig. 5A) (Fleming et al., 1997; Richmond and Jorgensen, 1999; Culetto et al., 2004; Towers et al., 2005). We first went on to look at the expression of fluorescently tagged LAChR/UNC-29 and LAChR/UNC-63 receptor subunits in the hpo-30 mutant animals (Francis et al., 2005; Rapti et al., 2011). We found that hpo-30 
A Paralysis on Levamisole

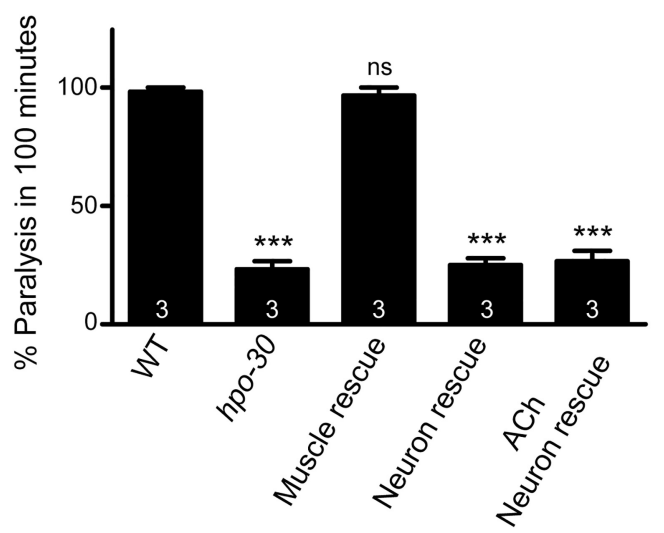

C
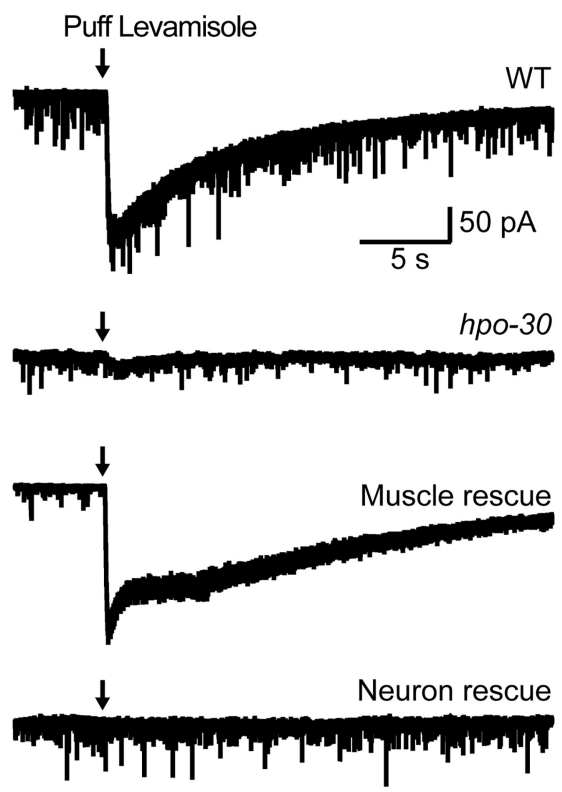

B

Paralysis on Muscimol

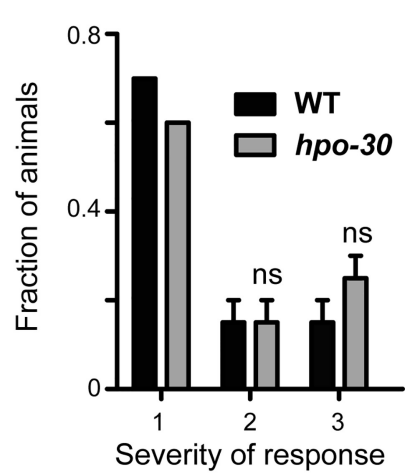

D

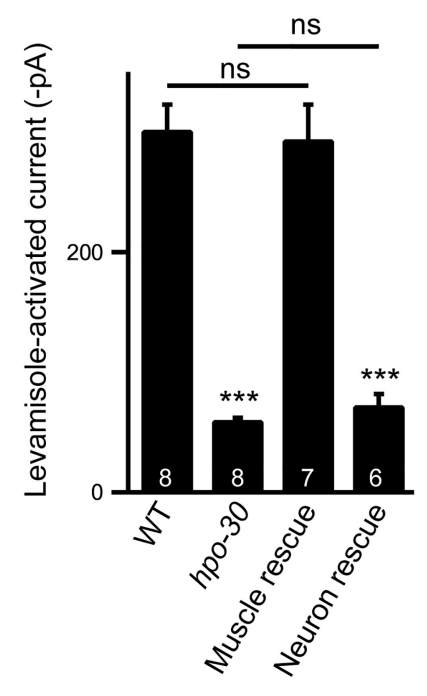

receptors are not localized at the synapse but are localized extrasynaptically in the regions of the muscle arms. To test whether LAChR/UNC-29 was localized to the body-wall muscle arms in the mutants, we studied the localization of LAChR/ UNC-29 at extrasynaptic regions using a strain in which the fluorescent protein tagRFP is introduced into the genomic locus of UNC-29 (Robert and Bessereau, 2007; Richard et al., 2013). We found that, in this line as well, there was a marked decrease in synaptic LAChR/UNC-29 in hpo-30 mutants (representative image in Fig. $5 D$ ), but no mislocalization of the receptors in the region of the body-wall muscle arms, indicated with CAM-1:: GFP, was seen (Fig. 5D, white brackets). Together, these results suggest that loss of hpo-30 decreases the synaptic abundance of LAChRs, and it is unlikely that the decrease in the LAChR levels is due to the mislocalization of the receptors at the site of muscle arms.

To further understand the function of HPO-30 in maintaining LAChRs at the synapse, we analyzed the behavior of hpo-30 mutants, lev- 8 mutants, and hpo30 ; lev-8 double mutants in the presence of levamisole. The resistance phenotypes of both single mutants and the double mutant were indistinguishable ( $h p o-30$ and hpo-30;lev-8, $p=0.4674, t=0.8018, \mathrm{df}=$ 4; Fig. $5 E$ ), thus suggesting that another subunit of LAChR functions in the same pathway as HPO-30.

Next, we wanted to test whether HPO-30 affected other receptors; we assayed for defects in the fluorescently tagged homomeric AChR/ACR-16 and the $\mathrm{GABA}_{\mathrm{A}} \mathrm{R} / \mathrm{UNC}-49$ (Bamber et al., 1999; Babu et al., 2011). It was found that the levels of ACR-16::GFP and UNC-49::GFP were not affected by the absence of $h p o-30$ (WT and $h p o-30, p=$ $1.0000, t=0.000$, df $=42$; Fig. $5 F$; and WT and $h p o-30, p=0.2650, t=1.135$, $\mathrm{df}=32$; Fig. $5 G)$.

These results suggest that HPO-30 Figure 4. hpo-30 mutants show defects in LAChR functions. $\boldsymbol{A}$, Levamisole-induced paralysis of WT, hpo-30 mutants, and site-specific rescue of HP0-30. Graph represents percentage of paralyzed animals at the 100 min time point. $B$, Behavior of WT and hpo-30 mutant animals in the presence of muscimol. Graph represents the fraction of $C$. elegans, which displayed the three level of severity of behavior in the presence of muscimol. The behavior of the animals was classified onto five categories, of which both WT and hpo-30 animals showed only three of the phenotypes: 1, C. elegans contract and relax briefly and then move away from the stimulus; 2, animals contract and relax while at the showing a small backward displacement; and 3, C. elegans contract and relax but fail to move backwards. $C$, Response to pressure ejection of levamisole on voltage-clamped body-wall muscle cells in animals with the following genotypes: WT, hpo-30, and muscle-specific rescue and neuron-specific rescue of HPO-30. D, Graph represents the amplitude of levamisole-activated currents for the animals recorded in C. Data are mean \pm SEM. ${ }^{* *} p<0.001$.

mutants showed a significant decrease in the fluorescence intensity of both UNC-63::YFP and UNC-29::GFP at the NMJ (WT and $h p o-30, p=0.0004, t=3.450$, df $=66$; Fig. $5 B$; WT and hpo-30, $p<0.0001, t=5.973, \mathrm{df}=43$; Fig. $5 C)$. The decreased levels of UNC-29::GFP were completely rescued by specifically expressing HPO-30 in the body-wall muscles (WT and hpo-30; Pmyo-3::HPO-30, $p=0.9668, t=0.0418, \mathrm{df}=44)$ but not in the neurons of the animals (WT and hpo-30; Prab-3::HPO-30, $p=$ $0.0001, t=6.234, \mathrm{df}=40$; Fig. $5 C$ ).

At the C. elegans NMJ, body-wall muscles extend projections called muscle arms to the nerve cord where they form en passant synapses with axons of motor neurons (White et al., 1986). The decrease in the fluorescence of LAChR/UNC-29 at the neuromuscular synapse in hpo-30 mutant animals could be because the function in muscles to maintain normal LAChR levels at the $C$. elegans NMJ. We next wanted to test whether HPO-30 affected the expression levels of LAChRs.

\section{Mutants of hpo-30 show normal expression of LAChR subunits}

Our experiments so far suggest that $h p o-30$ mutant animals show a decrease in LAChR levels at the NMJ. The decrease in the levels of LAChRs could be the result of decrease in the expression of genes coding for LAChR subunits. To check whether HPO-30 is required for gene expression, we compared the expression levels of LAChR subunits unc-29, unc-63, and $u n c-38$ in WT and hpo-30 mutant background by performing $\mathrm{qRT}$-PCR. There was no apparent difference in the 
A
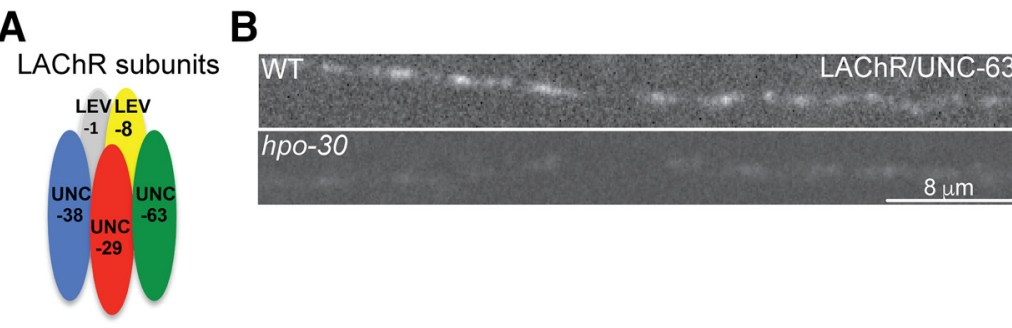

C

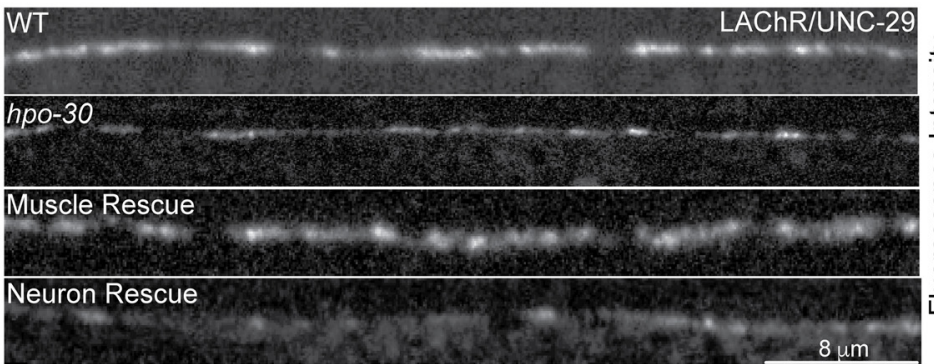

D

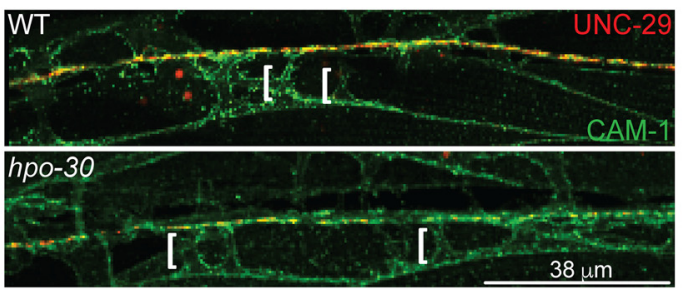

E
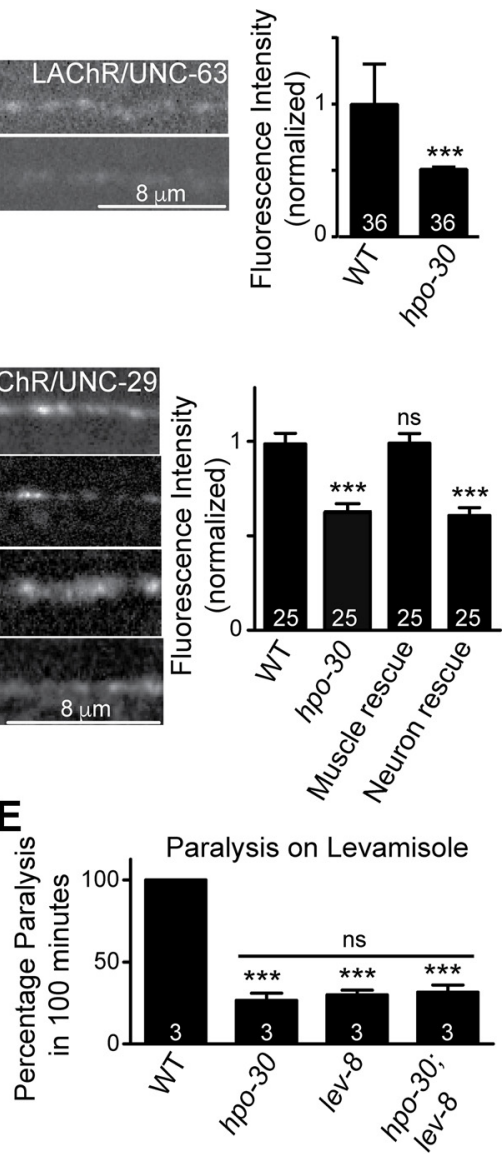

$\mathbf{F}$

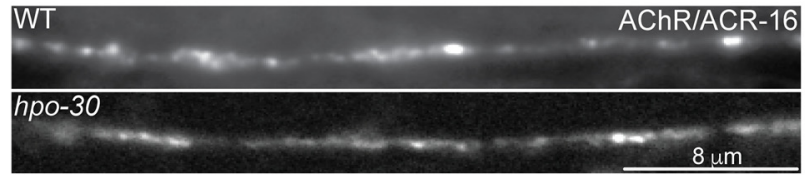

G
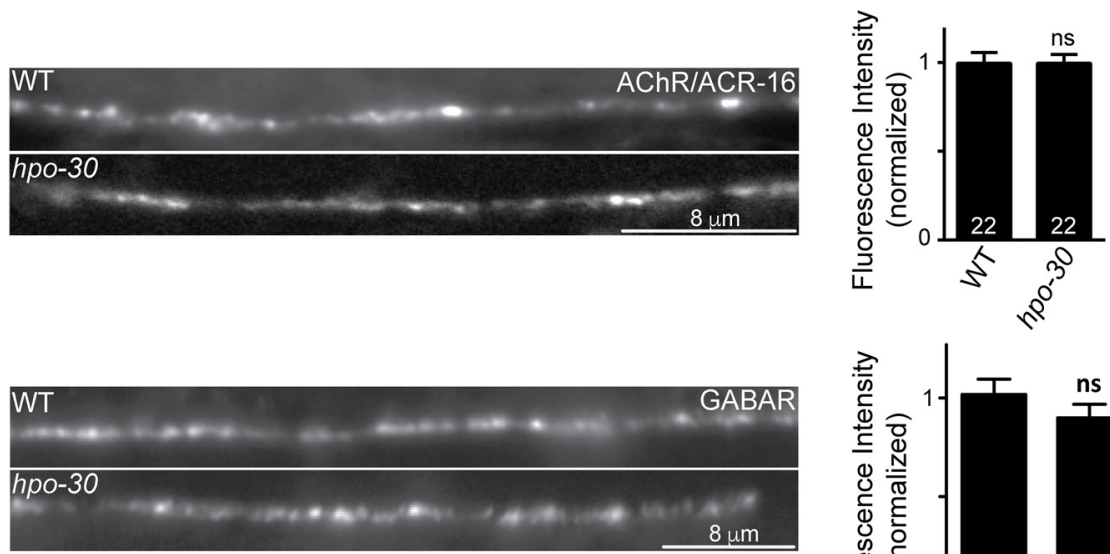

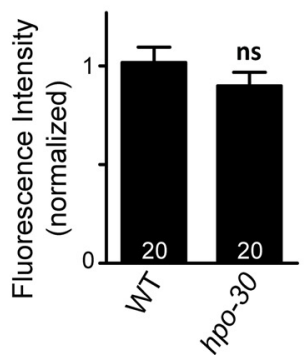

Figure 5. Mutants in hpo-30 show a decrease in synaptic LAChR abundance. $\boldsymbol{A}$, Diagram of five distinct subunits of the LAChRs. $\boldsymbol{B}$, Distribution of UNC-63::YFP at the NMJ in WT and hpo-30 animals and the fluorescence intensity of UNC-63::YFP in WT and hpo-30. The number of animals analyzed is indicated at the base of the bar graph for all graphs. $C$, Representative images and quantification for distribution of UNC-29:::GFP at the NMJ in WT, hpo-30, and HP0-30 rescue lines. D, Localization of UNC-29::RFP and CAM-1::GFP at the NMJ in WT and hpo-30 animals. Brackets indicate the muscle arms. $\boldsymbol{E}$, Levamisole-induced paralysis in WT, hpo-30, lev-8, and hpo-30;lev-8 mutants at the 100 min time point. $\boldsymbol{F}$, Representative images and quantification for the distribution of ACR-16::GFP at the NMJ in WT and hpo-30 animals. G, Representative images and quantification for the distribution of UNC-49::GFP at the NMJ in WT and hpo-30 mutants. Data are mean \pm SEM. ${ }^{* * *} p<0.001$.

transcript levels of the three subunits of LAChR tested in WT and $h p o-30$ mutants $(u n c-29, p=0.9526, t=0.06717, \mathrm{df}=2$; unc-38, $p=0.6726, t=0.4900, \mathrm{df}=2$; and lev-1, $p=0.4612$, $t=0.9046$, df $=2$; Fig. $6 A$ ). We also went on to quantitate the total amounts of UNC-29 and UNC-38 proteins in the animals by quantitative Western blotting using antibodies against UNC-29 and UNC-38, respectively. Again, we found that there was no difference between the UNC-29 and UNC-38 protein levels in WT and $h p o-30$ mutant animals (UNC-29, $p=0.8076, t=0.2773, \mathrm{df}=2$; and UNC-38, $p=0.8188, t=$ 0.2606 , $\mathrm{df}=2$; Fig. $6 B$ ). These results indicate that HPO-30 is unlikely to be required for the transcription or the translation of the LAChR subunits. To further analyze the association between HPO-30 and LAChRs, we analyzed the localization of 
A

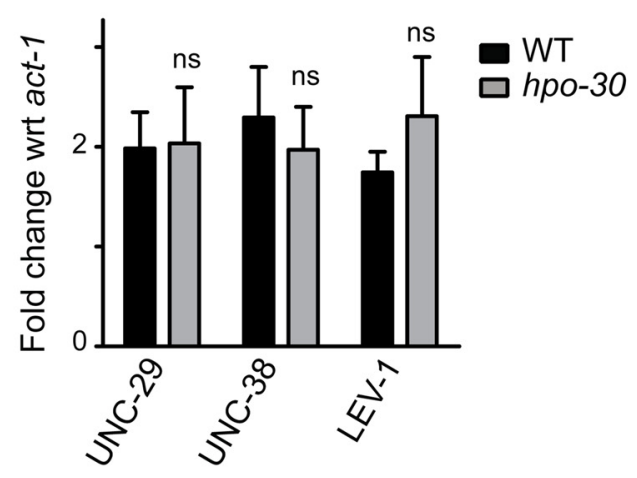

B

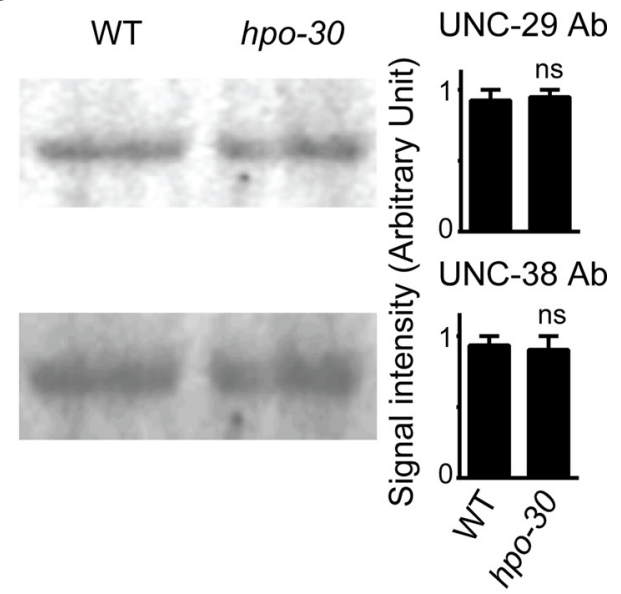

C

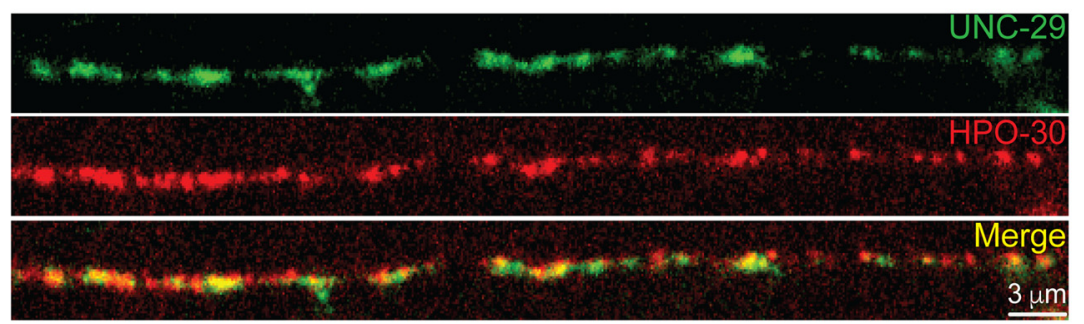

D

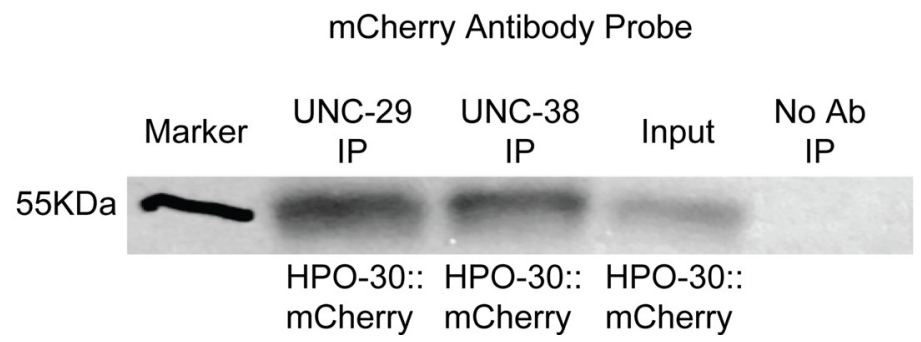

Figure 6. The expression level of LAChRs is unaffected in hpo-30 mutants. $\boldsymbol{A}, \mathrm{qPCR}$ experiments comparing the levels of unc-29, unc-38, and unc-63 in WT and $h p 0-30$ mutant animals. $\boldsymbol{B}$, Images and graphs of Western blots indicating the protein levels of UNC-29 and UNC-38 in WT and hpo-30 C. elegans. Data are mean \pm SEM.C, Distribution of HPO-30::mCherry and UNC-29::GFP in muscles. D, Coimmunoprecipitation of HPO-30::mCherry using anti-UNC-29 and anti-UNC-38 antibodies. As a control, the protein extracts are allowed to incubate with beads only without the antibody. The coimmunoprecipitated complex was then probed with an anti-mCherry antibody.

mCherry tagged HPO-30 expressed in body-wall muscles and observed overlapping expression with LAChRs/UNC-29 postsynaptically at the NMJ (Fig. 6C).

As HPO-30 showed genetic interaction with the LAChR subunit LEV-8 and also colocalized with UNC-29 (Figs. 5E, 6C), we hypothesized that HPO-30 might be functioning through a physical interaction where it may complex with LAChR subunits. To test this, we performed a coimmunoprecipitation experiment using C. elegans expressing HPO-30::mCherry in muscles. We used anti-UNC-29 and anti-UNC-38 to find the probable interaction between these LAChRs and HPO-30. Upon blotting with an antibody against mCherry, we found that HPO-30::mCherry was pulled down with UNC-29 and UNC-38 antibodies. As a control, we used protein lysate incubated with beads only and no antibody (Fig. 6D). These results demonstrate that HPO-30 shows a possible association with the LAChRs UNC-29 and UNC-38 and shows colocalization with UNC-29 at the NMJ. Together, these data indicate that HPO-30 may be required for stabilizing the LAChRs at the NMJ.
HPO-30 functions through Neuroligin to maintain normal levamisole puff response

The body-wall muscles in C. elegans cluster GABAergic receptors apposing GABAergic inputs and LAChRs and ACR-16 receptors apposing cholinergic inputs (White et al., 1976, 1986; Richmond and Jorgensen, 1999). Recent studies have shown that Neurexin (NRX-1) and NLG-1 are required for clustering $\mathrm{GABA}_{\mathrm{A}}$ receptors at the NMJ (Maro et al., 2015; Tu et al., 2015). To test whether HPO-30 could function through NRX-1 and/or NLG-1, we analyzed the behavioral responses of $h p o-30 ; n l g-1$ and $n r x-1$; hpo-30 double mutants toward aldicarb and levamisole along with their respective controls (i.e., single mutants for hpo-30, nlg-1, and $n r x-1)$. Surprisingly, we found that the hpo-30;nlg-1 mutants, but not the nrx-1;hpo-30 mutants, could completely suppress the resistance to aldicarb and levamisole phenotype that was seen in the hpo-30 mutants (aldicarb assay; WT and hpo-30;nlg-1, $p=0.6433, t=0.50$, $\mathrm{df}=4$; Fig. $7 A$ ). However, $n \lg -1$ and $n r x-1$ single mutants showed phenotypes similar to WT animals on aldicarb and 
A

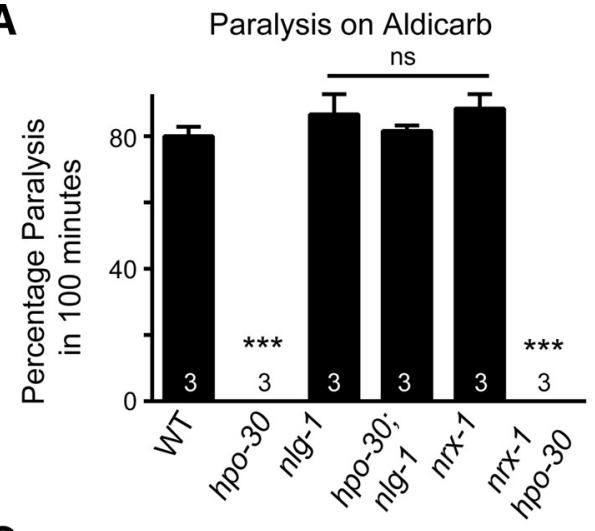

C
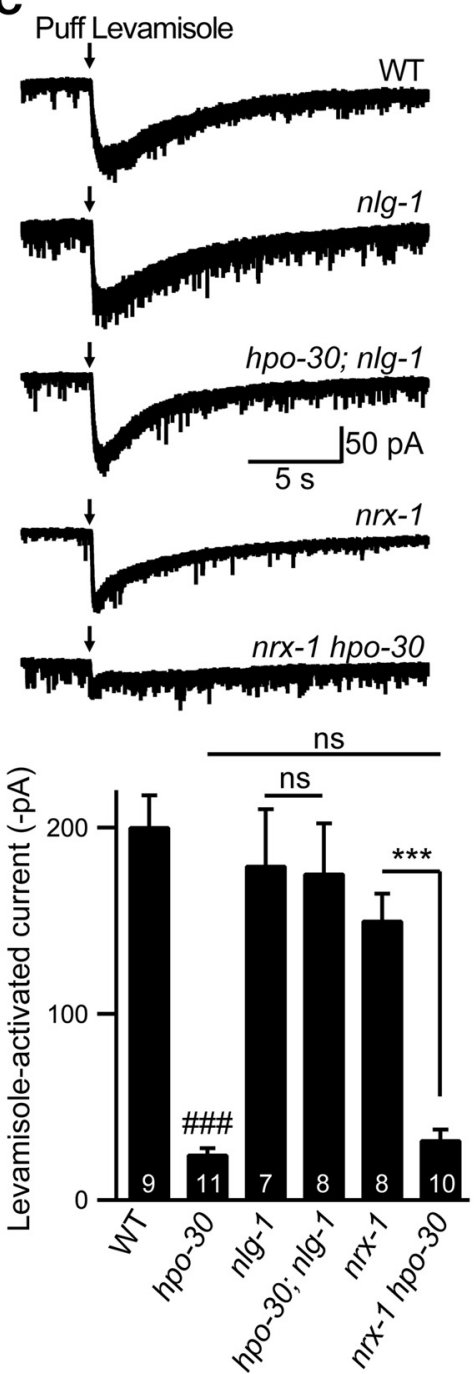

B

Paralysis on Levamisole

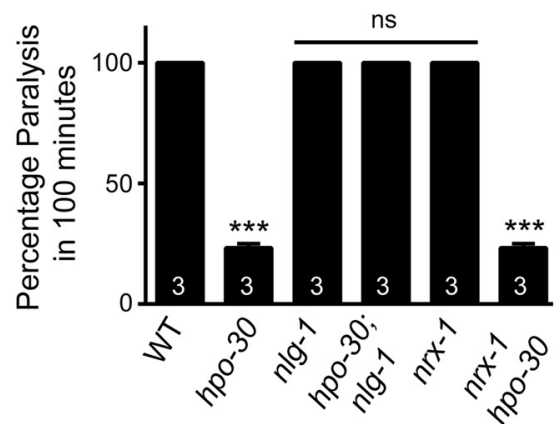

D $n l g-1$

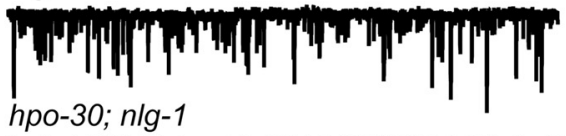

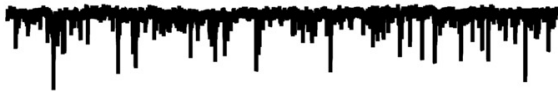

$n r x-1$

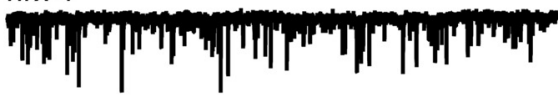

nrx-1 hpo-30
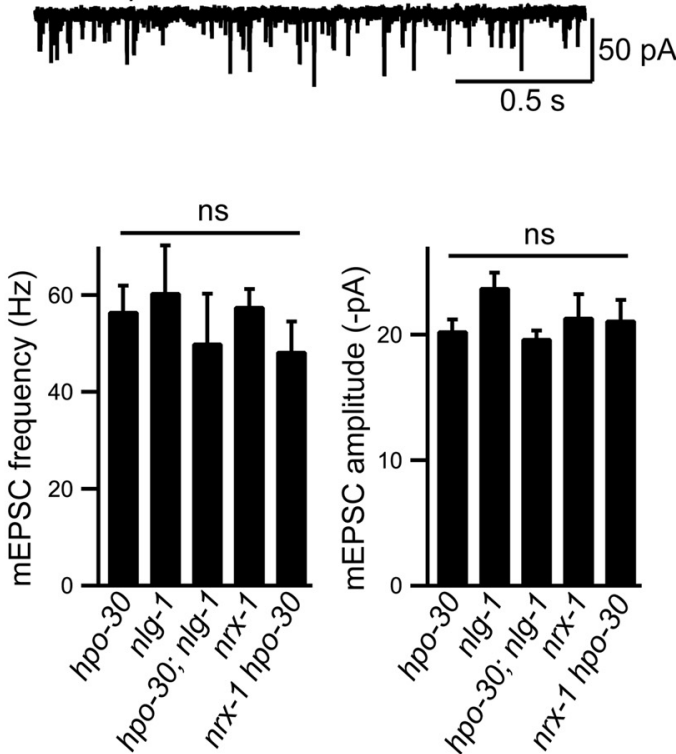

Figure 7. HPO-30 functions through NLG-1 to maintain LAChR function. A, Percentage paralysis of animals at the 100 min time point in WT (80\%), hpo-30 (0\%), nlg-1 (90\%), $n r x-1$ (90\%), hpo-30;nlg-1 (80\%), and $n r x-1$ hpo-30 (0\%) in the presence of aldicarb. B, Percentage paralysis of animals at 100 min in WT (100\%), hpo-30 (25\%), nlg-1 (100\%), nrx-1 (100\%), hpo-30;nlg-1 $(100 \%)$, and $n r x-1$ hpo-30 (25\%) upon exposure to levamisole. C, Currents recorded from voltage-clamped body-wall muscles in response to pressure-ejected levamisole in WT, $n l g-1$, $h p 0$-30; $n l g-1$, $n r x-1$, and $n r x-1$ hpo-30. Black arrow indicates the time of application of levamisole and summary data for levamisole-puff currents. $\boldsymbol{D}$, Representation of endogenous EPSCs recorded from body-wall muscles of adult C. elegans for the following genotypes: $n l g-1, h p 0-30 ; n l g-1, n r x-1$, and $n r x-1, h p o-30$ and graphs showing average frequency and amplitude of EPSCs recorded. Data are mean \pm SEM. ${ }^{* * *} p<0.001,{ }^{\# \#} p<0.001$.

levamisole (WT and $n l g-1, p=0.3739, t=1.000, \mathrm{df}=4$; and WT and $n r x-1, p=0.1890, t=1.581, \mathrm{df}=4)$. RNAi knockdown of $n l g-1$ and hpo-30 also confirmed our experiments performed with genetic mutants (data not shown).
To further understand the role of NLG-1 in maintaining postsynaptic LAChRs, we performed levamisole-puff response-based electrophysiological analysis on the hpo-30;nlg-1 and the $n r x-1$; hpo-30 double mutants. Again, we found that $n \lg -1$ and not $n r x-1$ 
could completely suppress the loss of levamisole puff response of hpo-30 mutants (WT and $h p o-30, p<0.0001, t=11.32$, $\mathrm{df}=18$; WT and $n l g-1, p=0.5356, t=0.6350, \mathrm{df}=14$; WT and $n r x-1$, $p=0.0403, t=2.244, \mathrm{df}=15 ; \mathrm{WT}$ and $h p o-30 ; n \lg -1, p=0.4315$, $t=0.8084, \mathrm{df}=15 ; \mathrm{WT}$ and $n r x-1$ hpo-30, $p<0.0001, t=9.911$, df $=17$; Fig. $7 C$ ).

We also recorded the endogenous EPSCs from the muscles in hpo-30;nlg-1 and nrx-1 hpo-30 mutant lines along with the single mutant controls and found that both the frequency and amplitude of the postsynaptic current were not significantly different from the single mutants (EPSC frequency; $h p o-30$ and $n l g-1, p=$ $0.4122, t=0.8419, \mathrm{df}=16 ;$ hpo-30 and $h p o-30 ; n \lg -1, p=0.5368$, $t=0.6322$, df $=15$; EPSC amplitude; $h p o-30$ and $n \lg -1, p=$ $0.0328, t=2.336, \mathrm{df}=16 ;$ hpo-30 and $h p o-30 ; n \lg -1, p=0.6583$, $t=0.4513, \mathrm{df}=15$; Fig. $7 D)$. Together, these results suggest that NLG-1 and NRX-1 are unlikely to be required for the functioning of ACR-16 receptors at the NMJ.

Our results indicate that HPO-30 could function through NLG-1 to maintain the LAChR-dependent functions at the NMJ.

\section{NLG-1 functions downstream of HPO-30}

Our data so far indicate that loss of $n l g-1$ could suppress the hpo-30 mutant phenotype. We also analyzed the stimulus-evoked muscle responsiveness in nlg-, hpo-30, and hpo-30;nlg-1 mutants. We found that the stimulus-evoked currents in the double mutants were also similar to the control values (evoked currents; hpo-30 and $n \lg -1, p=0.0007, t=4.203$, df $=16$; and $h p o-30$ and $h p o-30 ; n l g-1, p=0.9020, t=0.1253, \mathrm{df}=14$; charge transfer; $h p o-30$ and $n l g-1, p=0.0002, t=4.761, \mathrm{df}=16$; and $h p o-30$ and $h p o-30 ; n l g-1, p=0.0590, t=2.055, \mathrm{df}=14$; Fig. $8 A$ ).

As all the previous results indicate that the absence of $n \lg -1$ and hpo-30 could affect LAChR levels at the NMJ, we went on to examine the LAChR/UNC-29 levels in the hpo-30;nlg-1 double mutants. We analyzed the expression of UNC-29::tagRFP in hpo30, $n l g-1$, and $h p o-30 ; n l g-1$ genetic backgrounds. We observed a significant decrease in the florescence intensity of UNC-29 at the $\mathrm{NMJ}$ in the $h p o-30$ mutant background (WT and $h p o-30, p<$ $0.0001, t=8.283$, df = 49; Fig. $8 B$ ). However, in the $h p o-30$; $n \lg -1$ double mutants, the florescence intensity was comparable with WT animals (WT and hpo-30; $n \lg -1, p=0.2109, t=1.269$, $\mathrm{df}=$ 56 ; Fig. $8 B$ ). These results further indicate that $n l g-1$ suppresses the hpo-30 mutant phenotype to WT levels of LAChR/UNC-29 at the NMJ. Surprisingly, we also see a significant decrease in the LAChR/UNC-29 receptor levels in $n l g-1$ mutants (WT and $n l g-1$, $p<0.0001, t=5.3089$, df $=53$; Fig. $8 B$ ), which we are unable to explain, as there is no significant change in the levamisole puff response in these animals (Fig. 7C). This change in the UNC-29 receptor levels at the $\mathrm{NMJ}$ in the absence of $n l g-1$ may indicate that NLG-1 could have a possible function in maintaining the LAChRs at the NMJ.

Our data suggest that elevated NLG-1 levels could result in decreased LAChRs at the NMJ. To verify this hypothesis, we looked at the expression of LAChR/UNC-29 after overexpressing NLG-1 in muscles. We found that there is a marked reduction in the UNC-29::tagRFP levels at the NMJ compared with WT control animals $(p<0.0001, t=5.818, \mathrm{df}=57$; Fig. $8 C)$.

Finally, we wanted to test whether HPO-30 is required for maintaining NLG-1 levels at the NMJ. To do this, we imaged NLG-1::GFP in WT animals and in hpo-30 mutants. We found a significant increase in NLG-1 at the NMJ in hpo-30 mutants $(p<$ $0.0001, t=12.55$, df $=46$; Fig. $8 D$ ). These experiments further strengthened our hypothesis that NLG-1 could function downstream of HPO-30. Expression of HPO-30 is required to main- tain WT levels of NLG-1 at the synapse, and loss of $h p o-30$ shows an aberrant increase in the synaptic NLG-1 levels. Together, our data strongly suggest that HPO-30 maintains LAChR levels at the $\mathrm{NMJ}$ and is functioning through NLG-1 to maintain its function at the neuromuscular synapse.

\section{Discussion}

Neurotransmission occurs at specialized points of contacts between the presynaptic neuron and the postsynaptic neuron or muscle. The signaling at the NMJ demonstrates a high level of subcellular complexity, and we are still to get a clear understanding of the NMJ components and their signaling mechanisms. In this study, we set out to determine the function of a C. elegans claudin-like molecule HPO-30 at the NMJ. Our results indicate that the expression and function of HPO-30 in the body-wall muscles are required to maintain normal LAChR receptor levels at the NMJ. Mutants lacking this protein exhibit resistance to cholinergic but not GABAergic agonists, indicating that HPO-30 affects AChRs and not GABARs.

In C. elegans, two types of AChRs are present at the NMJ. Pharmacologically, one is preferentially gated by levamisole (LAChRs) and the other by nicotine (nAChR). The kinetics and the mechanism of regulation and clustering of these receptors are very different (Richmond and Jorgensen, 1999; Francis et al., 2005; Boulin et al., 2008, 2012; Simon et al., 2008; Gendrel et al., 2009; Babu et al., 2011; Rapti et al., 2011; Jensen et al., 2012; Richard et al., 2013; Briseño-Roa and Bessereau, 2014; PinanLucarré et al., 2014; Pierron et al., 2016; Pandey et al., 2017). Because loss of LAChRs causes resistance of the animal to levamisole, genetic screens based on levamisole-induced paralysis have contributed to the identification of proteins involved in functioning or assembly of LAChRs (Lewis et al., 1980; Fleming et al., 1997).

Previously, claudin-like proteins have been implicated in regulating structural aspect of the C. elegans nervous system. NSY-4 has been shown to affect AWC neuron specification by regulating calcium channels (Vanhoven et al., 2006), whereas HPO-30 has been implicated in governing dendritic branching in PVD neurons (Smith et al., 2013).

Our studies highlight the role of HPO-30 for the proper localization and hence activity of LAChRs while leaving the nAChR/ ACR-16 physiology unaffected. Our data also indicate a possible association between HPO-30 and LAChRs as we show that HPO-30 coimmunoprecipitates with LAChR subunits UNC-38 and UNC-29. Together, these results suggest that HPO-30 could have a role in the trafficking, assembly, stability, or clustering of the levamisole sensitive receptors at the $C$. elegans NMJ. Further experiments would be required to pinpoint the exact function of HPO-30 in LAChR maintenance.

Our results add to the growing body of work on the role of claudins in the nervous system, where we show that a claudin-like molecule acts at the neuromuscular synapse to maintain normal LAChR localization and function at the C. elegans NMJ.

The biogenesis and assembly of ionotropic receptors are a multistep process. Multiple proteins are involved in the folding, generation of membrane topology, and assembly of subunits into pentamers, trafficking and clustering of AChRs. The ligand-gated ion channels require auxiliary subunits for their trafficking, assembly, and function (for review, see Green, 1999; Keller and Taylor, 1999). Auxiliary proteins required for functioning and assembly of LAChRs in C. elegans include RIC-3, UNC-50, UNC74, NRA-2, NRA-4, and RSU-1. RIC-3 and UNC-50 are required for the efficient assembly, maturation, and trafficking of recep- 
A
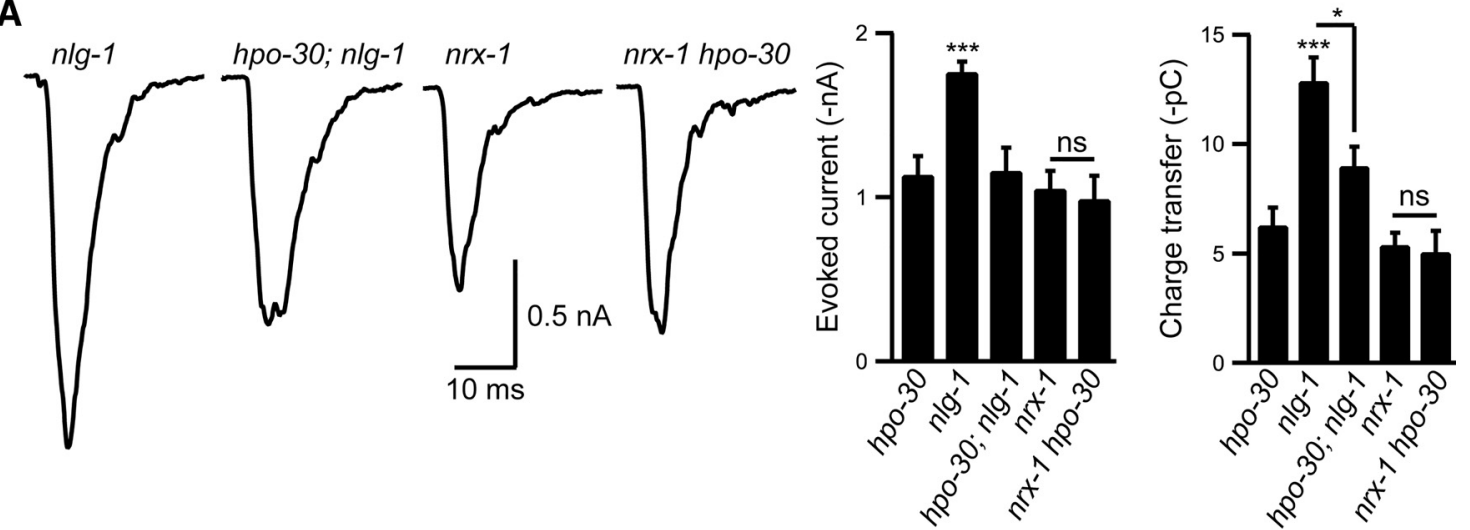

B
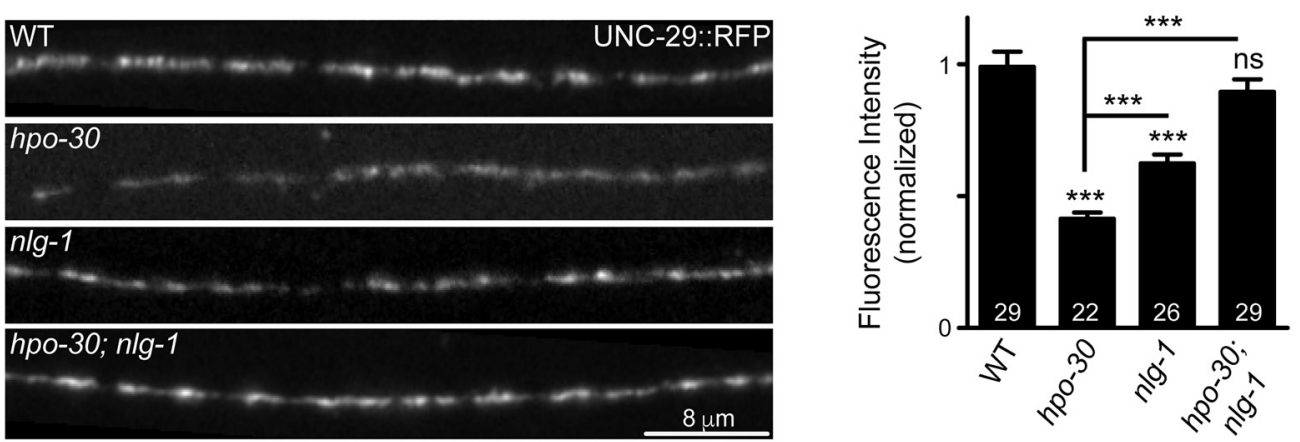

C

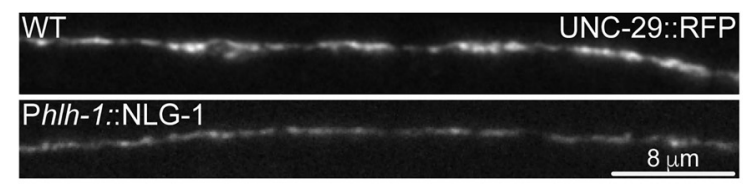

D
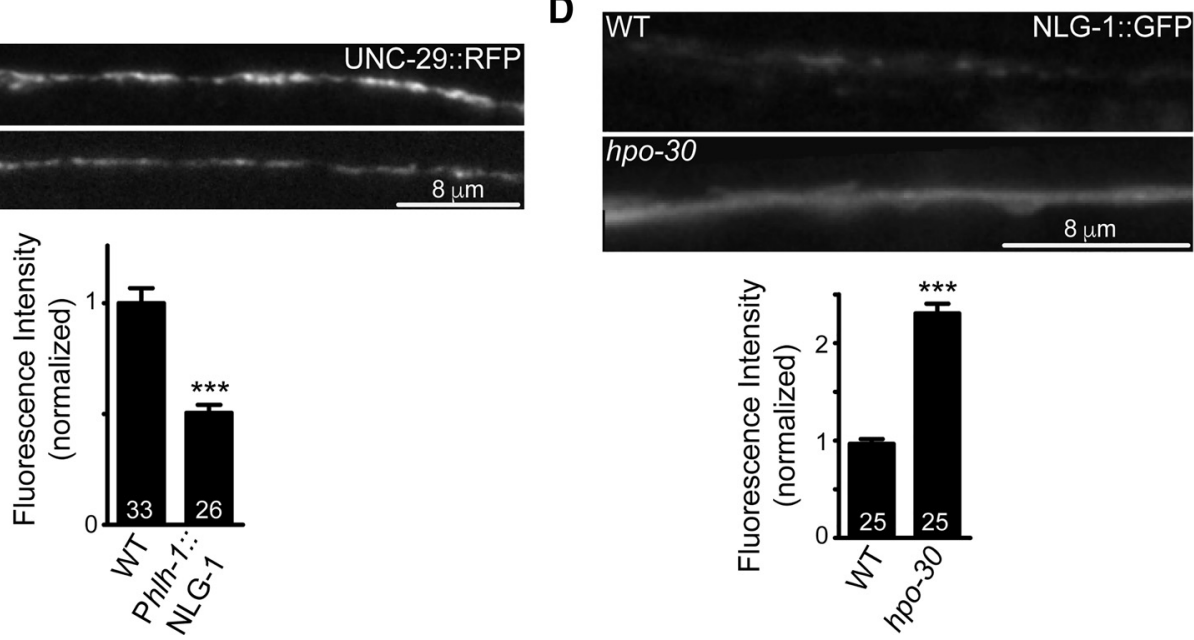

Figure 8. NLG-1 functions downstream of HPO-30. A, Stimulus-evoked responses measured from the body-wall muscles of $n / g-1, h p o-30 ; n l g-1, n r x-1$, and $n r x-1$ hpo-30 animals and summary data for amplitude of evoked currents and charge transfer. $\boldsymbol{B}$, Representative images and quantification for UNC-29::tagRFP in WT, $h p 0-30$, nlg-1, and hpo-30;nlg-1. C, Representative images and quantification for UNC-29::tagRFP in WT and NLG-1-overexpressing animals. D, Representative images and quantification for NLG-1::GFP in WT and hpo-30 mutant C. elegans. Data are mean \pm SEM. ${ }^{*} p<0.05,{ }^{* * *} p<0.001$.

tors from ER (Halevi et al., 2002; Eimer et al., 2007; Boulin et al., 2008; Jospin et al., 2009). Recently, NRA-2/Nicalin (Nicastrinlike protein), NRA-4/nodal modulator, and RSU-1 are proposed to regulate LAChRs subunit composition, stoichiometry, and distribution (Almedom et al., 2009; Pierron et al., 2016). LEV-9, LEV-10, and OIG-4 serve as an extracellular scaffold that forms a physical complex with the LAChRs and localize them at the synapse (Gendrel et al., 2009; Rapti et al., 2011; Briseño-Roa and Bessereau, 2014). Our work on HPO-30 might help in understanding the mechanism that regulates receptor clustering or localization at the synapse. In the $C$. elegans nervous system, acetylcholine serves as the main excitatory neurotransmitter, the presence of multiple auxiliary proteins might represent a means to increase the functional repertoire of ionotropic AChRs. It will be interesting to understand how HPO-30 functions with other modulators in selectively regulating levamisole-sensitive ion channels.

Finally, we have identified NLG-1 as an important molecule in maintaining LAChRs through HPO-30 at the NMJ. Mutants in $n l g-1$ have been previously shown to have defects in $\mathrm{GABA}_{\mathrm{A}}$ receptor clustering and for normal retrograde signaling across the NMJ in C. elegans (Hu et al., 2012; Maro et al., 2015; Tu et al., 2015; Tong et al., 2017). A previous study by Hu et al. (2012) has shown that $n r x-1$ and $n \lg -1$ inhibit the retrograde signal induced by the microRNA mir-1 and that this inhibition is mediated by the presynaptic protein Tomosyn. Our data indicate that, unlike 
the other two components involved in retrograde signaling (i.e., $n l g-1$ and tom-1), hpo-30 does not appear to affect the secretion of synaptic vesicles. Although these experiments indicate that HPO-30 may not be involved in the retrograde signaling pathway, further experiments delineating the role of HPO-30 in presynaptic cholinergic neurons may help get more insight on possible presynaptic functions of HPO-30 at the NMJ. We further show that NLG-1 levels are negatively regulated by HPO-30 and that $n l g-1 ; h p o-30$ mutants suppress the $h p o-30$ mutant phenotype and show behaviors similar to $n l g-1$ mutant animals, indicating that NLG-1 is likely to be functioning downstream of HPO-30. Further, our data also suggest a possible association between HPO-30 and the LAChR receptor subunits. Together, our results suggest that HPO-30 negatively regulates NLG-1 levels, which in turn appears to antagonize LAChR clustering at the synapse. Further experiments could allow for more mechanistic insights into the function of HPO-30 and NLG-1 function at the NMJ.

A growing body of evidence suggests that cell adhesion molecules present at the synapse are not merely structural components, but they are actively involved in regulation and modification of synapse function, synapse formation, and synaptic receptor function (for review, see Dalva et al., 2007). The claudin family of proteins are known to interact with the actin cytoskeleton via other proteins (for review, see Sawada et al., 2003). The actin cytoskeleton acts as an important regulator of synapse assembly and organization (for review, see Dillon and Goda, 2005). The postsynaptic receptor organization and maintenance are dependent on number of proteins, including cell adhesion proteins and PDZ domain containing proteins (for review, see Sheng and Hoogenraad, 2007). The PDZ domain containing intracellular C-terminal domain of NLG-1 facilitates the binding of postsynaptic scaffold proteins (Irie et al., 1997; Dresbach et al., 2004). These proteins interact directly or indirectly with the actin cytoskeleton and hence could regulate receptor organization (for review, see Sheng and Kim, 2011). One possible outcome of HPO-30 function via NLG-1 could be modulation of the actin cytoskeleton, which in turn could allow for changes in ion channel localization at the synapse.

The genetic interaction of HPO-30 with the synaptic cell adhesion protein NLG-1 might serve as a link between cell adhesion and the regulation of ion channel. Our results add to the evidence that cell adhesion molecules can have multiple functions at the synapse.

\section{References}

Almedom RB, Liewald JF, Hernando G, Schultheis C, Rayes D, Pan J, Schedletzky T, Hutter H, Bouzat C, Gottschalk A (2009) An ER-resident membrane protein complex regulates nicotinic acetylcholine receptor subunit composition at the synapse. EMBO J 28:2636-2649. CrossRef Medline

Angelow S, Ahlstrom R, Yu AS (2008) Biology of claudins. Am J Physiol Renal Physiol 295:F867-F876. CrossRef Medline

Arikkath J, Campbell KP (2003) Auxiliary subunits: essential components of the voltage-gated calcium channel complex. Curr Opin Neurobiol 13: 298-307. CrossRef Medline

Asano A, Asano K, Sasaki H, Furuse M, Tsukita S (2003) Claudins in Caenorhabditis elegans: their distribution and barrier function in the epithelium. Curr Biol 13:1042-1046. CrossRef Medline

Babu K, Hu Z, Chien SC, Garriga G, Kaplan JM (2011) The immunoglobulin super family protein RIG-3 prevents synaptic potentiation and regulates wnt signaling. Neuron 71:103-116. CrossRef Medline

Bamber BA, Beg AA, Twyman RE, Jorgensen EM (1999) The Caenorhabditis elegans unc-49 locus encodes multiple subunits of a heteromultimeric GABA receptor. J Neurosci 19:5348-5359. CrossRef Medline

Baran R, Castelblanco L, Tang G, Shapiro I, Goncharov A, Jin Y (2010)
Motor neuron synapse and axon defects in a C. elegans alpha-tubulin mutant. PLoS One 5:e9655. CrossRef Medline

Boulin T, Gielen M, Richmond JE, Williams DC, Paoletti P, Bessereau JL (2008) Eight genes are required for functional reconstitution of the Caenorhabditis elegans levamisole-sensitive acetylcholine receptor. Proc Natl Acad Sci U S A 105:18590-18595. CrossRef Medline

Boulin T, Rapti G, Briseño-Roa L, Stigloher C, Richmond JE, Paoletti P, Bessereau JL (2012) Positive modulation of a cys-loop acetylcholine receptor by an auxiliary transmembrane subunit. Nat Neurosci 15:13741381. CrossRef Medline

Brenner S (1974) The genetics of Caenorhabditis elegans. Genetics 77:71-94. Medline

Briseño-Roa L, Bessereau JL (2014) Proteolytic processing of the extracellular scaffolding protein LEV-9 is required for clustering acetylcholine receptors. J Biol Chem 289:10967-10974. CrossRef Medline

Calahorro F, Ruiz-Rubio M (2012) Functional phenotypic rescue of Caenorhabditis elegans neuroligin-deficient mutants by the human and rat NLGN1 genes. PLoS One 7:e39277. CrossRef Medline

Calahorro F, Ruiz-Rubio M (2013) Human alpha- and beta-NRXN1 isoforms rescue behavioral impairments of Caenorhabditis elegans neurexindeficient mutants. Genes Brain Behav 12:453-464. CrossRef Medline

Culetto E, Baylis HA, Richmond JE, Jones AK, Fleming JT, Squire MD, Lewis JA, Sattelle DB (2004) The Caenorhabditis elegans unc-63 gene encodes a levamisole-sensitive nicotinic acetylcholine receptor alpha subunit. J Biol Chem 279:42476-42483. CrossRef Medline

Dalva MB, McClelland AC, Kayser MS (2007) Cell adhesion molecules: signalling functions at the synapse. Nat Rev Neurosci 8:206-220. CrossRef Medline

Daniels SA, Ailion M, Thomas JH, Sengupta P (2000) egl-4 acts through a transforming growth factor-beta/SMAD pathway in Caenorhabditis elegans to regulate multiple neuronal circuits in response to sensory cues. Genetics 156:123-141. Medline

de la Cruz IP, Levin JZ, Cummins C, Anderson P, Horvitz HR (2003) sup-9, sup-10, and unc-93 may encode components of a two-pore $\mathrm{K}^{+}$channel that coordinates muscle contraction in Caenorhabditis elegans. J Neurosci 23:9133-9145. CrossRef Medline

Dillon C, Goda Y (2005) The actin cytoskeleton: integrating form and function at the synapse. Annu Rev Neurosci 28:25-55. CrossRef Medline

Dresbach T, Neeb A, Meyer G, Gundelfinger ED, Brose N (2004) Synaptic targeting of neuroligin is independent of neurexin and SAP90/PSD95 binding. Mol Cell Neurosci 27:227-235. CrossRef Medline

Eimer S, Gottschalk A, Hengartner M, Horvitz HR, Richmond J, Schafer WR, Bessereau JL (2007) Regulation of nicotinic receptor trafficking by the transmembrane Golgi protein UNC-50. EMBO J 26:4313-4323. CrossRef Medline

Fleming JT, Squire MD, Barnes TM, Tornoe C, Matsuda K, Ahnn J, Fire A, Sulston JE, Barnard EA, Sattelle DB, Lewis JA (1997) Caenorhabditis elegans levamisole resistance genes lev-1, unc-29, and unc-38 encode functional nicotinic acetylcholine receptor subunits. J Neurosci 17:58435857. CrossRef Medline

Francis MM, Evans SP, Jensen M, Madsen DM, Mancuso J, Norman KR, Maricq AV (2005) The ror receptor tyrosine kinase CAM-1 is required for ACR-16-mediated synaptic transmission at the C. elegans neuromuscular junction. Neuron 46:581-594. CrossRef Medline

Gally C, Eimer S, Richmond JE, Bessereau JL (2004) A transmembrane protein required for acetylcholine receptor clustering in Caenorhabditis elegans. Nature 431:578-582. CrossRef Medline

Gendrel M, Rapti G, Richmond JE, Bessereau JL (2009) A secreted complement-control-related protein ensures acetylcholine receptor clustering. Nature 461:992-996. CrossRef Medline

Goncalves A, Ambrósio AF, Fernandes R (2013) Regulation of claudins in blood-tissue barriers under physiological and pathological states. Tissue Barriers 1:e24782. CrossRef Medline

Green WN (1999) Ion channel assembly: creating structures that function. J Gen Physiol 113:163-170. CrossRef Medline

Halevi S, McKay J, Palfreyman M, Yassin L, Eshel M, Jorgensen E, Treinin M (2002) The C. elegans ric-3 gene is required for maturation of nicotinic acetylcholine receptors. EMBO J 21:1012-1020. CrossRef Medline

Hamazaki Y, Itoh M, Sasaki H, Furuse M, Tsukita S (2002) Multi-PDZ domain protein 1 (MUPP1) is concentrated at tight junctions through its possible interaction with claudin-1 and junctional adhesion molecule. J Biol Chem 277:455-461. CrossRef Medline 
Harada S, Hori I, Yamamoto H, Hosono R (1994) Mutations in the unc-41 gene cause elevation of acetylcholine levels. J Neurochem 63:439-446. CrossRef Medline

Heiskala M, Peterson PA, Yang Y (2001) The roles of claudin superfamily proteins in paracellular transport. Traffic 2:93-98. Medline

Hu Z, Hom S, Kudze T, Tong XJ, Choi S, Aramuni G, Zhang W, Kaplan JM (2012) Neurexin and neuroligin mediate retrograde synaptic inhibition in C. elegans. Science 337:980-984. CrossRef Medline

Irie M, Hata Y, Takeuchi M, Ichtchenko K, Toyoda A, Hirao K, Takai Y, Rosahl TW, Südhof TC (1997) Binding of neuroligins to PSD-95. Science 277:1511-1515. CrossRef Medline

Itoh M, Furuse M, Morita K, Kubota K, Saitou M, Tsukita S (1999) Direct binding of three tight junction-associated MAGUKs, ZO-1, ZO-2, and ZO-3, with the COOH termini of claudins. J Cell Biol 147:1351-1363. CrossRef Medline

Jensen M, Hoerndli FJ, Brockie PJ, Wang R, Johnson E, Maxfield D, Francis MM, Madsen DM, Maricq AV (2012) Wnt signaling regulates acetylcholine receptor translocation and synaptic plasticity in the adult nervous system. Cell 149:173-187. CrossRef Medline

Jospin M, Qi YB, Stawicki TM, Boulin T, Schuske KR, Horvitz HR, Bessereau JL, Jorgensen EM, Jin Y (2009) Neuronal acetylcholine receptor regulates the balance of muscle excitation and inhibition in Caenorhabditis elegans. PLoS Biol 7:e1000265. CrossRef Medline

Kang MG, Campbell KP (2003) Gamma subunit of voltage-activated calcium channels. J Biol Chem 278:21315-21318. CrossRef Medline

Keller SH, Taylor P (1999) Determinants responsible for assembly of the nicotinic acetylcholine receptor. J Gen Physiol 113:171-176. CrossRef Medline

Kim C, Forrester WC (2003) Functional analysis of the domains of the C. elegans Ror receptor tyrosine kinase CAM-1. Dev Biol 264:376-390. CrossRef Medline

Kovalenko OV, Yang XH, Hemler ME (2007) A novel cysteine cross-linking method reveals a direct association between claudin-1 and tetraspanin CD9. Mol Cell Proteomics 6:1855-1867. CrossRef Medline

Ladwein M, Pape UF, Schmidt DS, Schnölzer M, Fiedler S, Langbein L, Franke WW, Moldenhauer G, Zöller M (2005) The cell-cell adhesion molecule EpCAM interacts directly with the tight junction protein claudin-7. Exp Cell Res 309:345-357. CrossRef Medline

Lewis JA, Wu CH, Berg H, Levine JH (1980) The genetics of levamisole resistance in the nematode Caenorhabditis elegans. Genetics 95:905-928. Medline

Liu H, Li L, Wang W, Gong J, Yang X, Hu Z (2018) Spontaneous vesicle fusion is differentially regulated at cholinergic and GABAergic synapses. Cell Rep 22:2334-2345. CrossRef Medline

Maro GS, Gao S, Olechwier AM, Hung WL, Liu M, Özkan E, Zhen M, Shen K (2015) MADD-4/Punctin and neurexin organize C. elegans GABAergic postsynapses through neuroligin. Neuron 86:1420-1432. CrossRef Medline

Matter K, Balda MS (2003) Holey barrier: claudins and the regulation of brain endothelial permeability. J Cell Biol 161:459-460. CrossRef Medline

Mello C, Fire A (1995) DNA transformation. Methods Cell Biol 48:451482. CrossRef Medline

Mello CC, Kramer JM, Stinchcomb D, Ambros V (1991) Efficient gene transfer in C. elegans: extrachromosomal maintenance and integration of transforming sequences. EMBO J 10:3959-3970. Medline

Miller KG, Alfonso A, Nguyen M, Crowell JA, Johnson CD, Rand JB (1996) A genetic selection for Caenorhabditis elegans synaptic transmission mutants. Proc Natl Acad Sci U S A 93:12593-12598. CrossRef Medline

Norris AD, Lundquist EA (2011) UNC-6/netrin and its receptors UNC-5 and UNC-40/DCC modulate growth cone protrusion in vivo in C. elegans. Development 138:4433-4442. CrossRef Medline

Nurrish S, Ségalat L, Kaplan JM (1999) Serotonin inhibition of synaptic transmission: Galpha(0) decreases the abundance of UNC-13 at release sites. Neuron 24:231-242. CrossRef Medline

O’Brien BMJ, Palumbos SD, Novakovic M, Shang X, Sundararajan L, Miller DM 3rd (2017) Separate transcriptionally regulated pathways specify distinct classes of sister dendrites in a nociceptive neuron. Dev Biol 432: 248-257. CrossRef Medline

Pandey P, Bhardwaj A, Babu K (2017) Regulation of WNT signaling at the neuromuscular junction by the immunoglobulin superfamily protein RIG-3 in Caenorhabditis elegans. Genetics 206:1521-1534. CrossRef Medline

Papadopoulos MC, Saadoun S, Binder DK, Manley GT, Krishna S, Verkman AS (2004) Molecular mechanisms of brain tumor edema. Neuroscience 129:1011-1020. CrossRef Medline

Pierron M, Pinan-Lucarré B, Bessereau JL (2016) Preventing illegitimate extrasynaptic acetylcholine receptor clustering requires the RSU-1 protein. J Neurosci 36:6525-6537. CrossRef Medline

Pinan-Lucarré B, Tu H, Pierron M, Cruceyra PI, Zhan H, Stigloher C, Richmond JE, Bessereau JL (2014) C. elegans punctin specifies cholinergic versus GABAergic identity of postsynaptic domains. Nature 511:466470. CrossRef Medline

Rapti G, Richmond J, Bessereau JL (2011) A single immunoglobulindomain protein required for clustering acetylcholine receptors in C. elegans. EMBO J 30:706-718. CrossRef Medline

Richard M, Boulin T, Robert VJ, Richmond JE, Bessereau JL (2013) Biosynthesis of ionotropic acetylcholine receptors requires the evolutionarily conserved ER membrane complex. Proc Natl Acad Sci U S A 110:E1055E1063. CrossRef Medline

Richmond JE (2006) Electrophysiological recordings from the neuromuscular junction of C. elegans. WormBook 1-8.

Richmond JE, Jorgensen EM (1999) One GABA and two acetylcholine receptors function at the C. elegans neuromuscular junction. Nat Neurosci 2:791-797. CrossRef Medline

Robert V, Bessereau JL (2007) Targeted engineering of the Caenorhabditis elegans genome following Mos1-triggered chromosomal breaks. EMBO J 26:170-183. CrossRef Medline

Rubinstein E (2011) The complexity of tetraspanins. Biochem Soc Trans 39:501-505. CrossRef Medline

Sambrook J, Russell DW (2001) Molecular cloning: A Laboratory manual. Cold Spring Harbour, NY: Cold Spring Harbor Laboratory Press.

Sawada N, Murata M, Kikuchi K, Osanai M, Tobioka H, Kojima T, Chiba H (2003) Tight junctions and human diseases. Med Electron Microsc 36: 147-156. CrossRef Medline

Sheng M, Kim E (2011) The postsynaptic organization of synapses. Cold Spring Harb Perspect Biol 3:a005678. CrossRef Medline

Sheng M, Hoogenraad CC (2007) The postsynaptic architecture of excitatory synapses: a more quantitative view. Annu Rev Biochem 76:823-847. CrossRef Medline

Sieburth D, Ch'ng Q, Dybbs M, Tavazoie M, Kennedy S, Wang D, Dupuy D, Rual JF, Hill DE, Vidal M, Ruvkun G, Kaplan JM (2005) Systematic analysis of genes required for synapse structure and function. Nature 436:510-517. CrossRef Medline

Simon DJ, Madison JM, Conery AL, Thompson-Peer KL, Soskis M, Ruvkun GB, Kaplan JM, Kim JK (2008) The microRNA miR-1 regulates a MEF2-dependent retrograde signal at neuromuscular junctions. Cell 133:903915. CrossRef Medline

Simske JS, Hardin J (2011) Claudin family proteins in Caenorhabditis elegans. Methods Mol Biol 762:147-169. CrossRef Medline

Simske JS, Köppen M, Sims P, Hodgkin J, Yonkof A, Hardin J (2003) The cell junction protein VAB-9 regulates adhesion and epidermal morphology in C. elegans. Nat Cell Biol 5:619-625. CrossRef Medline

Singh AB, Sharma A, Dhawan P (2010) Claudin family of proteins and cancer: an overview. J Oncol 2010:541957. CrossRef Medline

Smith CJ, O'Brien T, Chatzigeorgiou M, Spencer WC, Feingold-Link E, Husson SJ, Hori S, Mitani S, Gottschalk A, Schafer WR, Miller DM 3rd (2013) Sensory neuron fates are distinguished by a transcriptional switch that regulates dendrite branch stabilization. Neuron 79:266-280. CrossRef Medline

Staab TA, Evgrafov O, Knowles JA, Sieburth D (2014) Regulation of synaptic nlg-1/neuroligin abundance by the skn-1/Nrf stress response pathway protects against oxidative stress. PLoS Genet 10:e1004100. CrossRef Medline

Tanaka M, Kamata R, Sakai R (2005a) EphA2 phosphorylates the cytoplasmic tail of claudin- 4 and mediates paracellular permeability. J Biol Chem 280:42375-42382. CrossRef Medline

Tanaka M, Kamata R, Sakai R (2005b) Phosphorylation of ephrin-B1 via the interaction with claudin following cell-cell contact formation. EMBO J 24:3700-3711. CrossRef Medline 
Tong XJ, López-Soto EJ, Li L, Liu H, Nedelcu D, Lipscombe D, Hu Z, Kaplan JM (2017) Retrograde synaptic inhibition is mediated by alphaneurexin binding to the alpha2delta subunits of N-type calcium channels. Neuron 95:326-340.e5. CrossRef Medline

Touroutine D, Fox RM, Von Stetina SE, Burdina A, Miller DM 3rd, Richmond JE (2005) acr-16 encodes an essential subunit of the levamisoleresistant nicotinic receptor at the Caenorhabditis elegans neuromuscular junction. J Biol Chem 280:27013-27021. CrossRef Medline

Towers PR, Edwards B, Richmond JE, Sattelle DB (2005) The Caenorhabditis elegans lev-8 gene encodes a novel type of nicotinic acetylcholine receptor alpha subunit. J Neurochem 93:1-9. CrossRef Medline

Tu H, Pinan-Lucarré B, Ji T, Jospin M, Bessereau JL (2015) C. elegans punctin clusters $\mathrm{GABA}(\mathrm{A})$ receptors via neuroligin binding and UNC-40/DCC recruitment. Neuron 86:1407-1419. CrossRef Medline

Turksen K, Troy TC (2004) Barriers built on claudins. J Cell Sci 117:24352447. CrossRef Medline

Van Itallie CM, Anderson JM (2006) Claudins and epithelial paracellular transport. Annu Rev Physiol 68:403-429. CrossRef Medline
Vanhoven MK, Bauer Huang SL, Albin SD, Bargmann CI (2006) The claudin superfamily protein nsy- 4 biases lateral signaling to generate left-right asymmetry in C. elegans olfactory neurons. Neuron 51:291-302. CrossRef Medline

Vashlishan AB, Madison JM, Dybbs M, Bai J, Sieburth D, Ch'ng Q, Tavazoie M, Kaplan JM (2008) An RNAi screen identifies genes that regulate GABA synapses. Neuron 58:346-361. CrossRef Medline

White JG, Southgate E, Thomson JN, Brenner S (1976) The structure of the ventral nerve cord of Caenorhabditis elegans. Philos Trans R Soc Lond B Biol Sci 275:327-348. CrossRef Medline

White JG, Southgate E, Thomson JN, Brenner S (1986) The structure of the nervous system of the nematode Caenorhabditis elegans. Philos Trans R Soc Lond B Biol Sci 314:1-340. CrossRef Medline

Zou W, Dong X, Broederdorf TR, Shen A, Kramer DA, Shi R, Liang X, Miller DM 3rd, Xiang YK, Yasuda R, Chen B, Shen K (2018) A dendritic guidance receptor complex brings together distinct actin regulators to drive efficient F-actin assembly and branching. Dev Cell 45:362-375.e3. CrossRef Medline 